\title{
Secreted Extracellular Vesicle Molecular Cargo as a Novel Liquid Biopsy Diagnostics of Central Nervous System Diseases
}

\author{
Sara Monteiro-Reis ${ }^{1,2}{ }^{(}$, Carina Carvalho-Maia ${ }^{1,2}{ }^{2}$ Genevieve Bart ${ }^{3}$, Seppo J. Vainio ${ }^{3} \mathbb{C}^{\circ}$, Juliana Pedro ${ }^{4}$, \\ Eunice R. Silva ${ }^{4}$, Goreti Sales ${ }^{5,6}\left(\mathbb{D}\right.$, Rui Henrique ${ }^{1,2,7}$ (1) and Carmen Jerónimo ${ }^{1,2,7, *(1)}$
}

1 Cancer Biology \& Epigenetics Group, Research Center, Portuguese Oncology Institute of Porto (CI-IPOP), R. Dr. António Bernardino de Almeida, 4200-072 Porto, Portugal; sara.raquel.reis@ipoporto.min-saude.pt (S.M.-R.); carina.carvalho.maia@ipoporto.min-saude.pt (C.C.-M.); rmhenrique@icbas.up.pt (R.H.)

2 Biobank, Department of Pathology, Portuguese Oncology Institute of Porto (IPOP), R. Dr. António Bernardino de Almeida, 4200-072 Porto, Portugal

3 Disease Networks Research Unit, Laboratory of Developmental Biology, Faculty of Biochemistry and Molecular Medicine, Infotech Oulu, Kvantum Institute, University of Oulu, 90570 Oulu, Finland; genevieve.Bart@oulu.fi (G.B.); seppo.vainio@oulu.fi (S.J.V.)

4 Psychology Service, Portuguese Oncology Institute of Porto (IPOP), R. Dr. António Bernardino de Almeida, 4200-072 Porto, Portugal; juliana.batista.pedro@ipoporto.min-saude.pt (J.P.); esilva@ipoporto.min-saude.pt (E.R.S.)

5 BioMark Sensor Research/Centre of Biological Engineering of Minho University, Campus de Gualtar, 4710-057 Braga, Portugal; goreti.sales@gmail.com

6 Department of Chemical Engineering, Faculty of Sciences and Technology, University of Coimbra, Rua Sílvio Lima, 3030-790 Coimbra, Portugal

check for updates

Citation: Monteiro-Reis, S.; Carvalho-Maia, C.; Bart, G.; Vainio, S.J.; Pedro, J.; Silva, E.R.; Sales, G.; Henrique, R.; Jerónimo, C. Secreted Extracellular Vesicle Molecular Cargo as a Novel Liquid Biopsy Diagnostics of Central Nervous System Diseases. Int. J. Mol. Sci. 2021, 22, 3267. https://doi.org/10.3390/ijms22063267

Academic Editor: Leonora Balaj

Received: 17 February 2021

Accepted: 20 March 2021

Published: 23 March 2021

Publisher's Note: MDPI stays neutral with regard to jurisdictional claims in published maps and institutional affiliations.

Copyright: (c) 2021 by the authors. Licensee MDPI, Basel, Switzerland. This article is an open access article distributed under the terms and conditions of the Creative Commons Attribution (CC BY) license (https:// creativecommons.org/licenses/by/ $4.0 /)$.
7 Department of Pathology and Molecular Immunology, Institute of Biomedical Sciences Abel Salazar, University of Porto (ICBAS-UP), Rua Jorge Viterbo Ferreira 228, 4050-513 Porto, Portugal

* Correspondence: carmenjeronimo@ipoporto.min-saude.pt; Tel.: +351-225-084-000

\begin{abstract}
Secreted extracellular vesicles (EVs) are heterogeneous cell-derived membranous granules which carry a large diversity of molecules and participate in intercellular communication by transferring these molecules to target cells by endocytosis. In the last decade, EVs' role in several pathological conditions, from etiology to disease progression or therapy evasion, has been consolidated, including in central nervous system (CNS)-related disorders. For this review, we performed a systematic search of original works published, reporting the presence of molecular components expressed in the CNS via EVs, which have been purified from plasma, serum or cerebrospinal fluid. Our aim is to provide a list of molecular EV components that have been identified from both nonpathological conditions and the most common CNS-related disorders. We discuss the methods used to isolate and enrich EVs from specific CNS-cells and the relevance of its components in each disease context.
\end{abstract}

Keywords: extracellular vesicles; central nervous system; biomarkers

\section{Introduction}

Extracellular vesicles (EVs) are cell-derived, membrane-bound structures, secreted into the extracellular environment by most, if not all, cell types. There is mounting evidence that EVs take part in control of normal physiological processes, in homeostasis control and in cell-to-cell communication within tissues and organs. Based on development of the EV field, different types of vesicles have been described, and include apoptotic bodies which range in size from 50 to $5000 \mathrm{~nm}$, microvesicles (50-1000 nm), exosomes (40-200 nm) and the more recently recognized exomeres [1-4].

The EVs have started to attract attention also as potential disease biomarkers and as new ways to study the control of cell biology. They seem to offer diagnostic capacity of organ dysfunctions via the body fluids as the components of the "liquid biopsy" type of sample. For example, solid tumors exhibit the elusive nature of transformed cells. They 
grow into organs but can metastasize to distant locations. The original tumor cells and their metastases secrete EVs and this has offered a promising way to diagnose cancers from its inception [5]. By studying the detailed molecular content of the cancer cell secreted EVs, tumor specific signatures may be defined and information about the changes in the associated biological processes gained.

In central nervous system (CNS) diseases, such as Alzheimer's disease, Parkinson's disease, multiple sclerosis, amyotrophic lateral sclerosis, gliomas, traumatic brain injury, stroke, schizophrenia and major depressive disorders, neuroscientists and neurologists cannot easily access the diseased tissues for diagnostic purposes. If brain biopsy is to be taken, it might not be representative of the common neurological disorder. Therefore, if the EVs that would be released from the CNS to systemic circulation could be identified reliably, this would provide a breakthrough to advance diagnostics of neurological diseases [6].

One of the challenges when working with EVs, particularly for CNS and CNS-related pathological conditions, is to ensure that the CNS-derived EVs can be isolated from the biological fluids (e.g., plasma (containing blood clotting agents), serum (without blood clotting agents) or cerebrospinal fluid (CSF)) and that these indeed would have originated from neural cells. Since EVs also contain the HLA-associated, self-depicting peptides and wealth of other types of cargo proteins of donor cells, such EV molecules may serve to identify specific organ level signatures, thus portraying the cell of origin. Since the EVs also have the ability to cross the blood-brain barrier (BBB) this raises the possibility that EV molecular content in biological fluids may reflect certain neuronal processes, as well [7]. Currently a relatively large body of literature documents the importance of EVs, but none has yet systematically summarized EVs molecular content in association with CNS and common CNS-related diseases. In this review, we provide a catalogue of CNS-derived EVs' molecular cargo, both in nonpathological and selected pathological conditions.

\section{Methods}

A PubMed search was conducted, with the query (extracellular vesicles OR exosomes OR microvesicles) AND (markers OR biomarkers) AND (brain OR central nervous system), with no time interval restraints. Only original studies written in English were considered. The retrieved records from the search were collected into the reference manager Endnote. All abstracts were critically assessed to select only those providing meaningful information related to the topic. Only studies using human cerebrospinal fluid (CSF), serum or plasma samples were included. A flow diagram with a summary of the methodology is provided in Figure 1. 

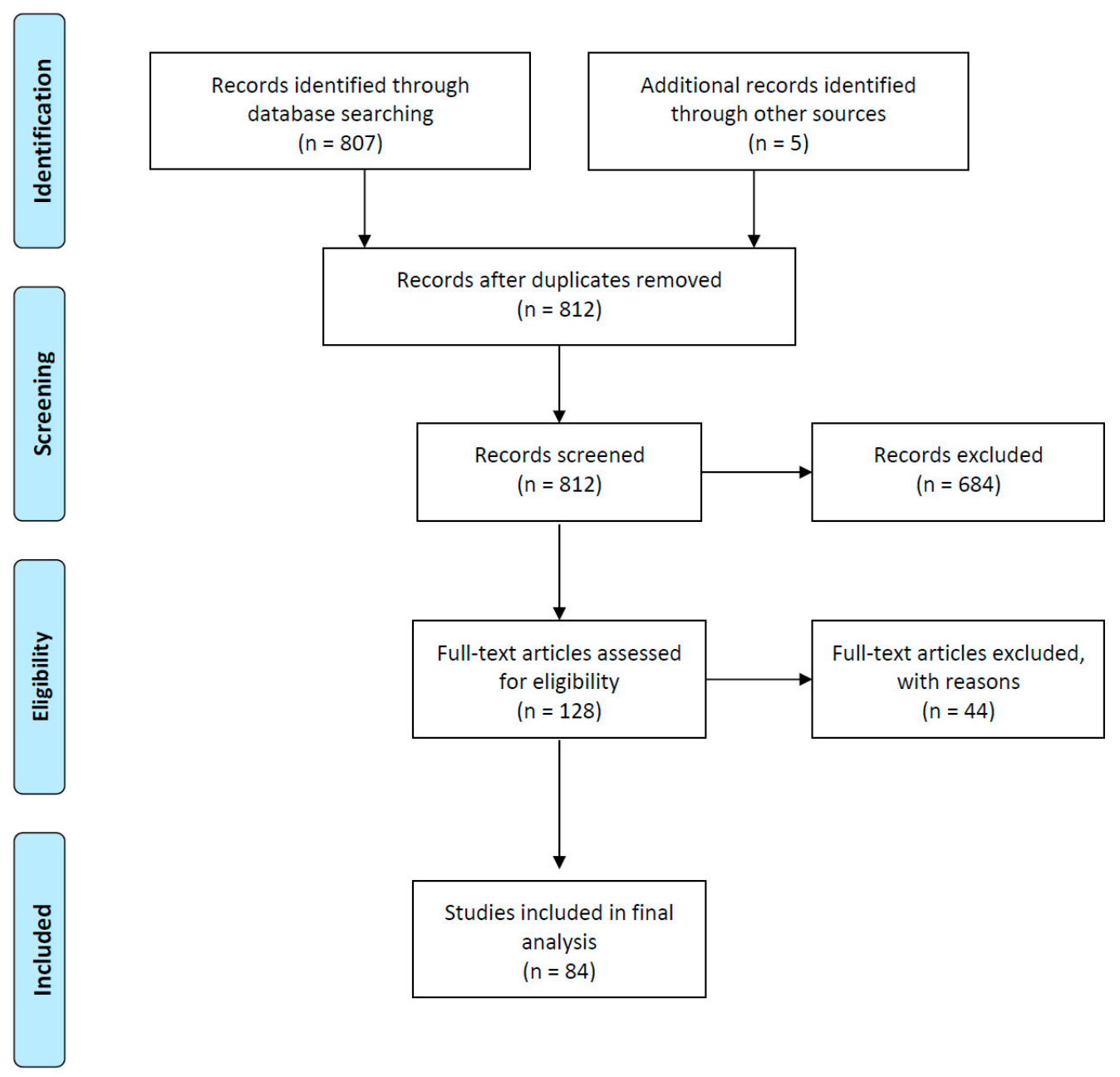

Figure 1. Flow diagram representing a summary of the conducted methodology for this review.

\section{Methods and Factors for Isolation of Central Nervous System Extracellular Vesicles in Liquid Biopsies}

Currently, as EVs are known to be able to cross the BBB, they are considered as potential biomarkers for monitoring CNS disorders as well as specific treatment responses. Of particular interest is the ability to characterize EVs based on their source, which may provide insight into the target disease. Although the majority of EVs research is performed through cell culture, the number of reports aiming at identifying biological fluids' EVs originated in different cell types is rising. Multiple methods (including ultracentrifugation, immunomagnetic beads, and size exclusion chromatography) can be used to separate mixed EVs (from multiple cell types) from different biological fluids [8]. This step may be taken further by using cell-specific protein markers to enrich for EVs of specific cell types from a mixed population of vesicles.

Specifically, EVs from the CNS are secreted from almost all cell types, including various types of neurons, astrocytes, oligodendrocytes, microglia and Schwann cells, and endothelial cells. EVs carry a variety of molecules related to neuronal function and neurotransmission in the brain. This contributes to the communication between nerve cells (for example, neuron-glia interaction), synaptic plasticity, and neuron development. Interestingly, Fiandaca et al. developed an immunoprecipitation-based method to isolate EVs rich in neuron sources from blood. This technology has been also used by others and consists of two steps: a preliminary separation of total EVs from plasma or serum samples using commercially available polymers for high-throughput particle precipitation, and immunoprecipitation with biotinylated antibodies against the neuron surface marker 
neuronal markers L1 cell adhesion molecule (L1CAM, CD171) [9]. Furthermore, L1CAM and the GluR2/3 subunits of glutamate receptors have been used for the identification of EVs that may be released from developing and mature hippocampal neurons [10,11]. Hence, using this method, EVs of neuronal origin may be enriched and evaluated based on proteins, lipids and nucleic acids.

Although neuron-derived EVs are a common target in several studies, researchers are also interested in isolating EVs originating from other CNS cells, aiming also to translate via the EVs the origin of CNS-related diseases. The above-mentioned methodology can also be used to enrich for EVs from other cellular origins with antibodies against specific cell surface components. For example, for astrocytic-derived EVs enrichment, glial fibrillary acidic protein (GFAP), glutamine aspartate transporter (GLAST), and glutamine synthetase (GLUL) have been suggested to be specific enough to obtain CNS related EVs [12]. Additionally, for EVs originated in oligodendrocytes, myelin proteolipid protein (PLP) and $2^{\prime}, 3^{\prime}$-cyclic nucleotide $3^{\prime}$-phosphodiesterase (CNP) have been proposed as specific enough to identify the cell from which the EVs derived [13] (Figure 2).
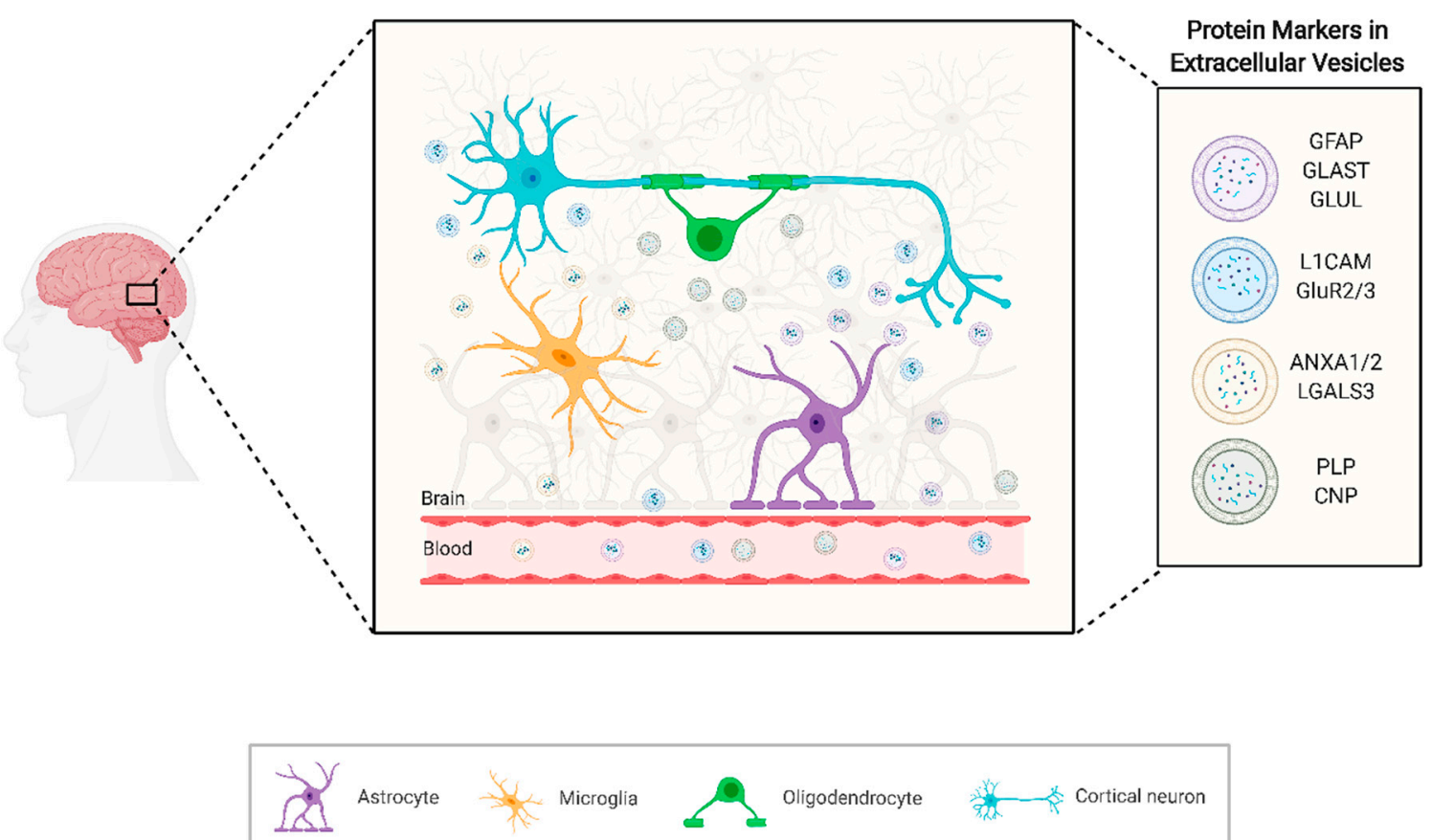

Figure 2. Schematic representation of the brain microenvironment, its main cellular components and how the brain-bloodbarrier permeability allows for extracellular vesicles to reach circulation. Created with BioRender.com.

The application of specific immunoaffinity-based methodology for the isolation of CNS-related EVs in biological fluids, applied to different CNS diseases research, has led to promising results $[9,14]$. Once the enriched fraction of EVs is obtained, either surface or cargo content can be analyzed using different approaches according to the molecular target of interest, such as proteomics (e.g., mass spectrometry, Western blot or enzyme-linked immunosorbent assays) and/or transcriptomics methodologies (e.g., high-throughput RNA sequencing or RT-qPCR). This opens a new avenue for research, using CNS-derived EVs as vehicles for disease monitoring.

\section{Central Nervous System Disease-Related Biomarkers in Extracellular Vesicles}

CNS-related disorders, including neurodegenerative diseases, such as Alzheimer's (AD) and Parkinson's (PD) diseases, malignant tumors, such as gliomas, and psychiatric disorders, are very different pathological conditions, but share common features: anatomical origin and difficult early diagnosis. The existing liquid biopsies and imaging biomarkers 
are rather imperfect, because their dynamic range does not cover the entire course of the disease, and their classification accuracy is lower than the level accepted for clinical practice, thus, precluding their routine implementation. Thus, the use of CNS-enriched EVs and their molecular content as biomarkers for these specific pathological conditions may revolutionize the clinical management of these patients. Indeed, a growing number of studies within this field have been published in the last few years. To simplify, a summary of the main publications retrieved from the database query can be found in Tables 1 and 2, referring to either cargo or surface molecules, respectively [9,12,15-97] (Figure 3).

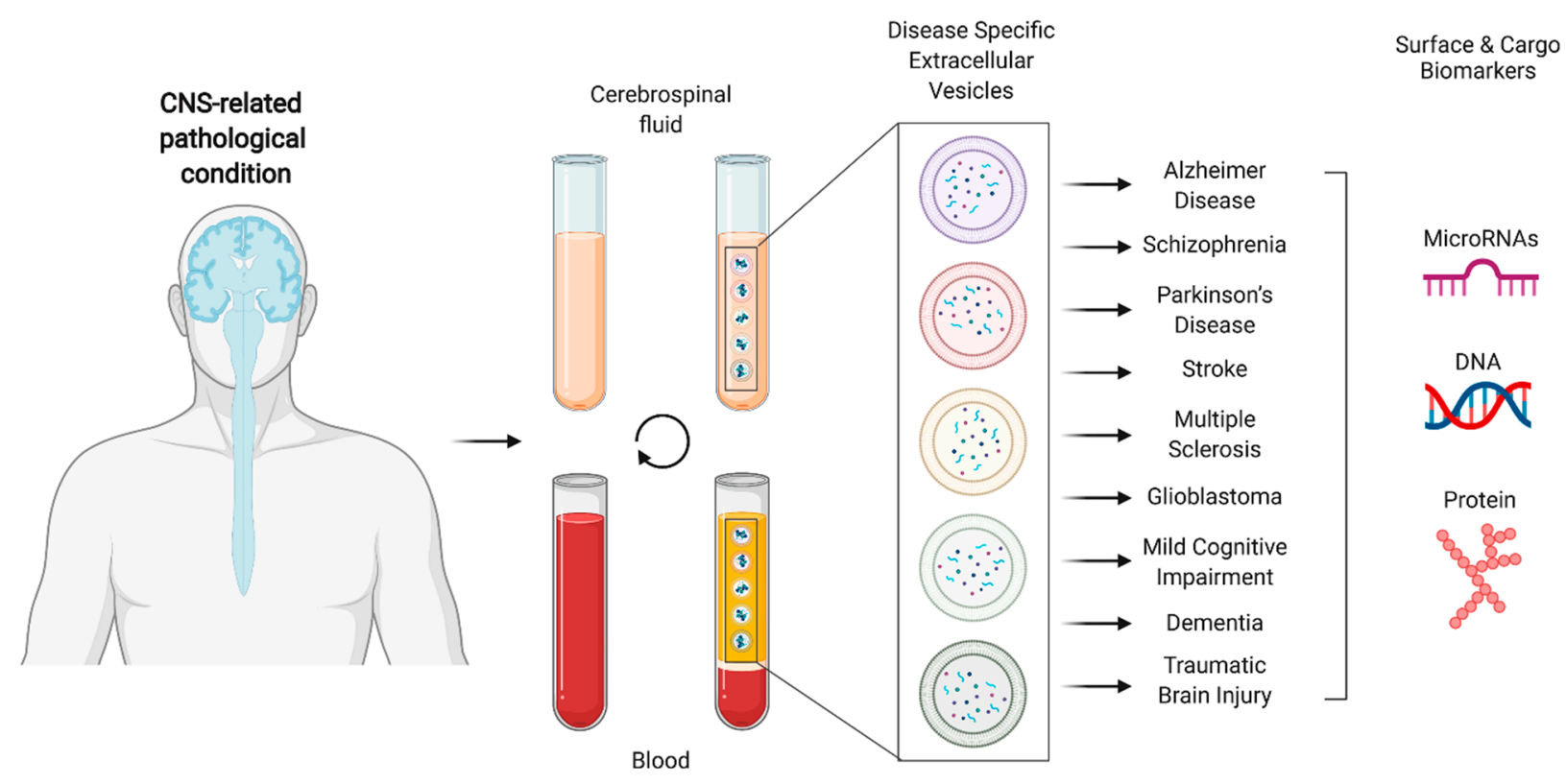

Figure 3. Schematic representation of the use of extracellular vesicles in liquid biopsies for identification of specific central nervous system (CNS)-related pathological conditions. Created with BioRender.com (accessed on 20 March 2021).

Alzheimer's disease (AD) is neurodegenerative disorder characterized by memory loss and behavioral changes. EVs have been studied as a potential diagnostic marker for AD. This disease has a complex progression including early development of neuronal dysplasia, angiogenic changes, release of inflammatory mediators by CNS glial and peripheral immune cells, and development of extracellular amyloid- $\beta(\mathrm{A} \beta)$ fibrils that deposit in the brain as amyloid plaques, and impair synaptic plasticity [98]. At the molecular level, the extracellular deposition of insoluble amyloid- $\beta$ A $\beta$ peptide plaques (39-43 amino acids produced by amyloid precursor protein, APP, peptides) occurs, which can interact with regulatory proteins to phosphorylate the microtubule-associated protein tau. The increase of phosphorylated tau protein (P-S396-tau, P-T181-tau) and A $\beta 42$ detected in plasma EVs is associated with increased risk for $\mathrm{AD}$ [98]. Of note, both $\mathrm{A} \beta$ and tau are secreted by neurons through the release of EVs $[12,26,36,56,90]$. Moreover, some authors also studied molecules found in EVs from patients suffering from mild cognitive impairment. Their memory has deficits that do not significantly affect daily functioning, but are often regarded and treated as early phase $\mathrm{AD}[52,55,99]$. 
Table 1. Extracellular vesicles protein and protein-coding genes transcripts as biomarkers associated with central nervous system pathological conditions.

\begin{tabular}{|c|c|c|c|c|c|c|c|}
\hline Molecule & Disease & Sample Type & Sample Grouping and Size & $\begin{array}{c}\text { Patients Gender and } \\
\text { Mean Age }\end{array}$ & EVs Isolation Method & Key Findings & Ref. \\
\hline $\begin{array}{c}\text { pSer312, } \\
\text { p-panTyr-IRS-1 }\end{array}$ & $\mathrm{AD}$ & Plasma & $\begin{array}{l}\text { Patients } \\
(\mathrm{N}=24)\end{array}$ & $14 q+10 \sigma^{\top}(73 \mathrm{yrs})$ & $\begin{array}{l}\text { Thromboplastin-D + } \\
\text { ExoQuick }^{\circledR} \text { (System } \\
\text { Biosciences) } \\
\text { + L1CAM IP }\end{array}$ & $\begin{array}{l}\text { Markers of brain insulin resistance in } \\
\text { NDEVs associate with atrophy in AD. }\end{array}$ & [29] \\
\hline $\begin{array}{l}\text { NPTX2, } \\
\text { NRXN2a, } \\
\text { AMPA4, } \\
\text { NLGN1 }\end{array}$ & $\mathrm{AD}$ & Plasma & $\begin{array}{c}\text { C.S.S.: } \\
\text { Patients }(\mathrm{N}=28) \\
\text { HC }(\mathrm{N}=28) \\
\text { L.S.: } \\
\text { Patients }(\mathrm{N}=18+18), \mathrm{HC} \\
(\mathrm{N}=18)\end{array}$ & $\begin{array}{c}\text { C.S.S.: Patients and } \\
\text { HC-16 }+12 \sigma^{\top}(73 \text { yrs }) ; \\
\text { L.S.: } \\
\text { Patients and HC-8\%+ } \\
10 \sigma^{\top}(69 \& 78 \text { yrs })\end{array}$ & $\begin{array}{l}\text { Thromboplastin-D + } \\
3000 \times g\left(30^{\prime} \text { at } 4^{\circ} \mathrm{C}\right)+ \\
\text { ExoQuick }^{\circledR} \\
+ \text { L1CAM IP }\end{array}$ & $\begin{array}{l}\text { Reduction of the marker levels in NDEVs } \\
\text { may be indicative of the extent of cognitive } \\
\text { loss and reflect progression of the severity } \\
\text { of AD. }\end{array}$ & [35] \\
\hline Tau & $\mathrm{AD}$ & Plasma & $\begin{array}{l}\text { AD patients }(\mathrm{N}=20) \\
\text { MCI patients }(\mathrm{N}=10) \\
\text { HC }(\mathrm{N}=10)\end{array}$ & $\begin{array}{l}\mathrm{AD}-11+9+9 \sigma^{7}(75 \mathrm{yrs}) \\
\mathrm{MCI}-5+5+5 \sigma^{\top}(76 \mathrm{yrs}) \\
\mathrm{HC}-7 q+3 \sigma^{\top}(76 \mathrm{yrs})\end{array}$ & $\begin{array}{l}\text { Thrombin }+6000 \times g\left(20^{\prime}\right. \\
\left.\text { at } 4{ }^{\circ} \mathrm{C}\right)+ \text { ExoQuick } \\
+ \text { L1CAM IP }\end{array}$ & $\begin{array}{l}\text { Tau was found free-floating with a small } \\
\text { component inside EVs; full-length Tau was } \\
\text { higher inside EVs than in free solution. }\end{array}$ & [36] \\
\hline SNAP-25 & $\mathrm{AD}$ & Serum & $\begin{array}{l}\text { AD patients }(\mathrm{N}=24) \\
\mathrm{HC}(\mathrm{N}=17)\end{array}$ & $\begin{array}{l}\mathrm{AD}-16 q+80^{7}(78 \mathrm{yrs}) \\
\mathrm{HC}-13++40^{\top}(77 \mathrm{yrs})\end{array}$ & $\begin{array}{l}\text { 10,000× } g\left(10^{\prime} \text { at RT }\right)+ \\
\text { ExoQuick } \\
+ \text { L1CAM IP }\end{array}$ & $\begin{array}{l}\text { The levels of SNAP-25 carried by NDEVs } \\
\text { were reduced in AD patients (sensitivity } \\
87.5 \% \text {, specificity } 70.6 \% \text { ). }\end{array}$ & [53] \\
\hline $\begin{array}{l}\mathrm{N}-123 \text { tau, } \\
\mathrm{N}-224 \text { tau }\end{array}$ & $\mathrm{AD}$ & Serum & $\begin{array}{c}\text { Patients w/CSF+ } \\
\text { biomarkers }(\mathrm{N}=4) \text {, patients } \\
\text { w/CSF- biomarkers }(\mathrm{N}=4)\end{array}$ & n.m. & $\begin{array}{c}4000 \times g\left(20^{\prime} \text { at } 4^{\circ} \mathrm{C}\right)+ \\
\text { ExoQuick }{ }^{\circledR} \\
+ \text { L1CAM IP }\end{array}$ & $\begin{array}{c}\mathrm{N}-224 \text { tau was present in NDEVs, while } \\
\mathrm{N}-123 \text { tau showed comparable } \\
\text { concentrations in both NDEVs and } \\
\text { peripherally derived EVs. }\end{array}$ & [56] \\
\hline BACE1-AS & $\mathrm{AD}$ & Plasma & $\begin{array}{l}\text { AD patients }(\mathrm{N}=72) \\
\mathrm{HC}(\mathrm{N}=62)\end{array}$ & $\begin{array}{l}\mathrm{AD}-38 \%+340^{7} \\
(74 \mathrm{yrs}) \\
\mathrm{HC}-39 \%+230^{7} \\
(72 \mathrm{yrs})\end{array}$ & $\begin{array}{l}\text { Thrombin }+14,000 \times g\left(5^{\prime}\right. \\
\left.\text { at } 4^{\circ} \mathrm{C}\right)+3000 \times g\left(15^{\prime} \text { at }\right. \\
\left.4^{\circ} \mathrm{C}\right)+ \text { ExoQuick }^{\circledR}\end{array}$ & $\begin{array}{c}\text { EVs BACE1-AS transcript levels in AD } \\
\text { patients were significantly higher compared } \\
\text { with the HC (sensitivity } 87.5 \% \text {, } \\
\text { specificity } 61.3 \% \text { ) }\end{array}$ & [96] \\
\hline
\end{tabular}


Table 1. Cont.

\begin{tabular}{|c|c|c|c|c|c|c|c|}
\hline Molecule & Disease & Sample Type & Sample Grouping and Size & $\begin{array}{c}\text { Patients Gender and } \\
\text { Mean Age }\end{array}$ & EVs Isolation Method & Key Findings & Ref. \\
\hline $\begin{array}{l}\text { SYP, } \\
\text { SYNPO, } \\
\text { SYT2, } \\
\text { NRGN, } \\
\text { GAP43, } \\
\text { SYN1 }\end{array}$ & $\begin{array}{l}\text { AD and } \\
\text { FTD }\end{array}$ & Plasma & $\begin{array}{c}\text { C.S.S.: } \\
\text { AD patients }(\mathrm{N}=12), \\
\text { FTD patients }(\mathrm{N}=16), \mathrm{HC} \\
(\mathrm{N}=28) \\
\text { L.S.: } \\
\text { AD patients }(\mathrm{N}=9), \text { FTD } \\
\text { patients }(\mathrm{N}=10) \\
\text { HC }(\mathrm{N}=19)\end{array}$ & $\begin{array}{c}\text { C.S.S.: } \\
\text { AD-6o+ } 6 \sigma^{7}(74 \text { yrs }) \\
\text { FTD-4+ } 12 \sigma^{7}(64 \text { yrs }) \\
\text { L.S.: } \\
\text { AD-7 }+2 \sigma^{7}(82 \text { yrs }) \\
\text { FTD-5 }+5 \sigma^{7}(63 \text { yrs })\end{array}$ & $\begin{array}{l}\text { Thromboplastin-D + } \\
3000 \times g\left(30^{\prime} \text { at } 4^{\circ} \mathrm{C}\right)+ \\
\text { ExoQuick }{ }^{\circledR} \\
+ \text { L1CAM IP }\end{array}$ & $\begin{array}{l}\text { SYP, SYNPO, SYT2, and NRGN levels were } \\
\text { significantly lower in patients with FTD } \\
\text { and AD than in HC. Some markers were } \\
\text { decreased years before dementia in FTD } \\
\text { and AD patients. }\end{array}$ & [22] \\
\hline Tau & $\begin{array}{l}\mathrm{AD} \text { and } \\
\mathrm{PD}\end{array}$ & Plasma & $\begin{array}{l}\text { AD patients }(\mathrm{N}=106) \\
\text { PD patients }(\mathrm{N}=91) \\
\text { HC }(\mathrm{N}=106)\end{array}$ & $\begin{array}{l}\mathrm{AD}-49++57 \sigma^{7}(70 \mathrm{yrs}) \\
\mathrm{PD}-26 q+65 \sigma^{7}(65 \mathrm{yrs}) \\
\mathrm{HC}-48 q+58 \sigma^{7}(67 \mathrm{yrs})\end{array}$ & $\begin{array}{l}2000 \times g\left(15^{\prime}\right)+ \\
\text { ultracentrifugation }+ \\
\text { L1CAM IP }\end{array}$ & $\begin{array}{c}\text { Tau was significantly higher in PD patients } \\
\text { than HCs, but not in AD patients, and } \\
\text { correlated } \\
\text { with CSF tau. }\end{array}$ & [25] \\
\hline pS1292-LRRK2 & PD & CSF & $\begin{array}{c}\text { PD patients: } \\
\text { LRRK2+ mutation }(\mathrm{N}=19) \\
\text { LRRK2- }(\mathrm{N}=19) \\
\text { HC: } \\
\text { LRRK2+ }(\mathrm{N}=39) \\
\text { LRRK2- }(\mathrm{N}=5)\end{array}$ & 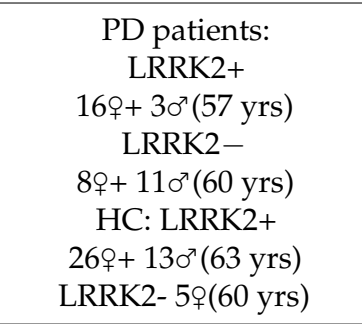 & $\begin{array}{l}10,000 \times g\left(30^{\prime} \text { at } 4^{\circ} \mathrm{C}\right)+ \\
\quad \text { ultracentrifugation }\end{array}$ & $\begin{array}{l}\text { pS1292-LRRK2 levels in CSF EVs were near } \\
\text { saturated in most subjects, 10-fold higher } \\
\text { than in urinary EVs, irrespective of LRRK2 } \\
\text { mutation status or PD diagnosis. }\end{array}$ & [30] \\
\hline $\begin{array}{c}\text { Akt, } \\
\text { p-mTOR, } \\
\text { p-Tyr-IRS-1 }\end{array}$ & PD & Serum & PD patients $(\mathrm{N}=60)$ & $17 q+43 \sigma^{\top}(60 \mathrm{yrs})$ & $\begin{array}{c}4500 \times g\left(20^{\prime} \text { at } 4^{\circ} \mathrm{C}\right)+ \\
\text { ExoQuick }{ }^{\circledR} \\
+ \text { L1CAM IP }\end{array}$ & $\begin{array}{l}\text { Exenatide-treated patients had elevated } \\
\text { expression of tyrosine phosphorylation of } \\
\text { IRS-1 and of downstream targets, total Akt } \\
\text { and p-mTOR. }\end{array}$ & [54] \\
\hline$\alpha$-synuclein & $\mathrm{PD}$ & Plasma & $\begin{array}{l}\text { PD patients }(\mathrm{N}=267), \mathrm{HC} \\
(\mathrm{N}=215)\end{array}$ & $\begin{array}{l}\mathrm{PD}-119++145 \sigma^{\top}(66 \mathrm{yrs}) \\
\mathrm{HC}-999+116 \sigma^{\top}(66 \mathrm{yrs})\end{array}$ & $\begin{array}{l}2000 \times g\left(15^{\prime}\right)+ \\
\text { ultracentrifugation }+ \\
\text { L1CAM IP }\end{array}$ & $\begin{array}{l}\text { Levels of } \alpha \text {-synuclein in EVs were } \\
\text { substantially higher in PD patients than in } \\
\text { HC. A significant correlation between } \\
\alpha \text {-synuclein found on EVs and disease } \\
\text { severity was observed. }\end{array}$ & [18] \\
\hline
\end{tabular}


Table 1. Cont.

\begin{tabular}{|c|c|c|c|c|c|c|c|}
\hline Molecule & Disease & Sample Type & Sample Grouping and Size & $\begin{array}{c}\text { Patients Gender and } \\
\text { Mean Age }\end{array}$ & EVs Isolation Method & Key Findings & Ref. \\
\hline$\alpha$-synuclein & PD & Serum & $\begin{array}{l}\text { PD patients: } \\
\text { Tremor type }(\mathrm{N}=22) \\
\text { Non-tremor }(\mathrm{N}=16) \\
\text { essential tremor }(\mathrm{ET}) \\
\text { patients }(\mathrm{N}=21) \\
\text { HC }(\mathrm{N}=18)\end{array}$ & 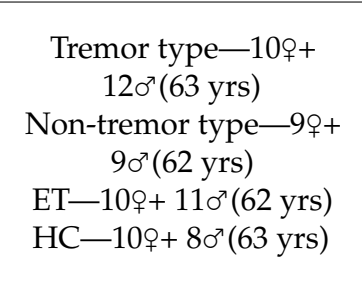 & $\begin{array}{l}3000 \times g \text { for }\left(15^{\prime} \text { at } 4{ }^{\circ} \mathrm{C}\right) \\
+ \text { ExoQuick } \\
+ \text { L1CAM IP }\end{array}$ & $\begin{array}{l}\alpha \text {-synuclein levels were lower in the PD } \\
\text { group than in the ET and HC. Levels were } \\
\text { lower in the NTD group than in the TD } \\
\text { group. } \alpha \text {-synuclein was found to } \\
\text { moderately aid in PD diagnosis } \\
\text { (AUC }=0.675 \text { ) and had a potential to } \\
\text { diagnose NTD (AUC }=0.761) .\end{array}$ & [72] \\
\hline$\alpha$-synuclein & PD & Plasma & $\begin{array}{l}\text { Early-stage PD patients } \\
(\mathrm{N}=36), \\
\text { Advanced PD patients } \\
(\mathrm{N}=17), \\
\text { iRBD patients }(\mathrm{N}=20), \mathrm{HC} \\
(\mathrm{N}=21)\end{array}$ & 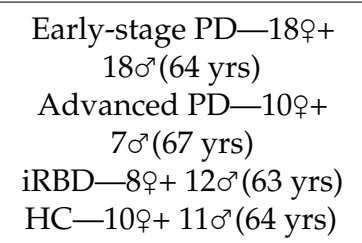 & $\begin{array}{c}2000 \times g\left(15^{\prime}\right)+ \\
\text { ultracentrifugation }+ \\
\text { L1CAM IP }\end{array}$ & $\begin{array}{l}\alpha \text {-synuclein levels in NDEVs were } \\
\text { significantly higher in patients with } \\
\text { early-stage PD compared with HCs. } \\
\text { Longitudinally increased } \alpha \text {-synuclein were } \\
\text { associated with higher risk for motor } \\
\text { symptom progression in PD. }\end{array}$ & [88] \\
\hline $\begin{array}{l}\text { Aß1-42, } \\
\text { p-Tau-S396, } \\
\text { NRGN, } \\
\text { SYP, } \\
\text { SYT1, } \\
\text { SYNPO }\end{array}$ & MCI & Plasma & $\begin{array}{c}\text { MCI patients }(\mathrm{N}=61) \\
\mathrm{HC}(\mathrm{N}=76)\end{array}$ & $\begin{array}{c}\mathrm{MCI}-39 q+22 \sigma^{\top}(70 \mathrm{yrs}) \\
\mathrm{HC}-47 q+29 \sigma^{7}(68 \mathrm{yrs})\end{array}$ & $\begin{array}{l}\text { Thrombin }+10,000 \mathrm{rpm} \\
\left(5^{\prime}\right)+ \\
\text { ExoQuick }^{\circledR} \\
+ \text { L1CAM IP }\end{array}$ & $\begin{array}{l}\text { NDEVs concentrations of A } \beta 1-42 \text { were } \\
\text { significantly increased while NRGN, } \\
\text { synaptophysin, synaptotagmin, and } \\
\text { synaptopodin levels were significantly } \\
\text { decreased in patients with MCI. }\end{array}$ & [52] \\
\hline $\begin{array}{l}\text { apoA1, } \\
\text { apoE, } \\
\text { apoJ, } \\
\text { AnnexinV, } \\
\text { Aß-42 }\end{array}$ & $\begin{array}{l}\text { MCI, AD } \\
\text { and } \\
\text { PD }\end{array}$ & CSF & $\begin{array}{c}\text { MCI patients }(\mathrm{N}=21) \\
\text { AD patients }(\mathrm{N}=27) \\
\text { PD patients }(\mathrm{N}=28) \\
\text { young } \mathrm{HC}(\mathrm{N}=15) \\
\text { middle-aged } \mathrm{HC}(\mathrm{N}=21) \\
\text { older } \mathrm{HC}(\mathrm{N}=23)\end{array}$ & 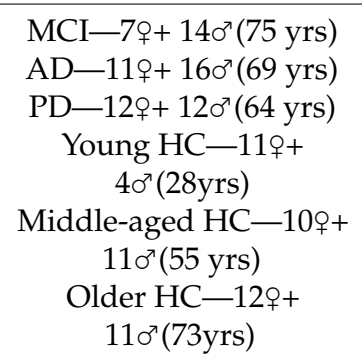 & Flow cytometric assay & $\begin{array}{c}\text { ApoE and Aß-42-positive particle } \\
\text { concentrations were reduced in middle and } \\
\text { older age subjects, whereas apoAI } \\
\text { increased with age. ApoAI and annexin V } \\
\text { levels were reduced in MCI and/or AD } \\
\text { patients vs. HCs. }\end{array}$ & [21] \\
\hline
\end{tabular}


Table 1. Cont.

\begin{tabular}{|c|c|c|c|c|c|c|c|}
\hline Molecule & Disease & Sample Type & Sample Grouping and Size & $\begin{array}{c}\text { Patients Gender and } \\
\text { Mean Age }\end{array}$ & EVs Isolation Method & Key Findings & Ref. \\
\hline $\begin{array}{l}\text { GSN, } \\
\text { BCHE }\end{array}$ & DLB & Plasma & $\begin{array}{l}\text { DLB patients }(\mathrm{N}=19) \\
\text { AD patients }(\mathrm{N}=10) \\
\text { HC }(\mathrm{N}=20)\end{array}$ & 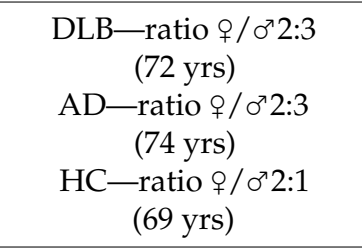 & $\begin{array}{c}2500 \times g\left(15^{\prime}\right)+16,000 \times \\
g\left(10^{\prime}\right)+\text { SEC }\end{array}$ & $\begin{array}{l}\text { Gelsolin decreased levels were found on } \\
\text { EVs from DLB patients, compared to HCs } \\
\text { and to AD patients. }\end{array}$ & [59] \\
\hline $\begin{array}{l}\text { P-tau, } \\
\text { Aß1-42, } \\
\text { NRGN, } \\
\text { REST }\end{array}$ & $\begin{array}{l}\text { MCI and } \\
\text { AD }\end{array}$ & Plasma & $\begin{array}{c}\text { MCI patients }(\mathrm{N}=20) \\
\text { AD patients }(\mathrm{N}=10) \\
\text { MCI-to-AD }(\mathrm{ADC}) \text { patients } \\
(\mathrm{N}=20) \\
\mathrm{HC}(\mathrm{N}=10)\end{array}$ & $\begin{array}{l}\mathrm{MCI}-79+13 \sigma^{7}(69 \mathrm{yrs}) \\
\mathrm{ADC}-9++11 \sigma^{7}(75 \mathrm{yrs}) \\
\mathrm{AD} \text { and } \mathrm{HC}-\mathrm{n} . \mathrm{m} .\end{array}$ & $\begin{array}{l}\text { Thromboplastin-D + } \\
\text { ExoQuick }^{\circledR} \\
\text { + L1CAM IP }\end{array}$ & $\begin{array}{l}\text { Abnormal NDEVs levels of P-tau, Aß1-42, } \\
\text { NRGN and REST accurately predicted } \\
\text { conversion of MCI to AD dementia. }\end{array}$ & [26] \\
\hline $\begin{array}{l}\text { Tau, } \\
\text { APP, } \\
\text { pTau-T181, } \\
\text { A } \beta 42\end{array}$ & $\begin{array}{l}\text { MCI and } \\
\text { AD }\end{array}$ & Plasma & $\begin{array}{l}\text { MCI patients }(\mathrm{N}=12) \\
\text { mild AD patients }(\mathrm{N}=12) \\
\text { moderate } \mathrm{AD} \text { patients } \\
(\mathrm{N}=12) \\
\text { severe AD patients }(\mathrm{N}=20) \\
\mathrm{HC}(\mathrm{N}=12)\end{array}$ & 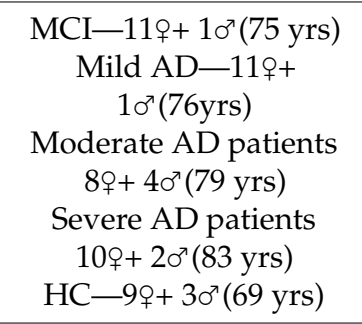 & $\begin{array}{l}2000 \times g\left(20^{\prime}\right)+10,000 \times \\
g\left(20^{\prime}\right)+\text { Total Exosome } \\
\text { Isolation reagent } \\
\quad(\text { Invitrogen } \\
\text { TM })\end{array}$ & $\begin{array}{l}\text { Abnormal APP levels and pTau-T181/tTau } \\
\text { ratio in EVs demonstrated a high accuracy } \\
\text { to define MCI and AD staging. }\end{array}$ & [90] \\
\hline $\begin{array}{l}\text { FN1, } \\
\text { GFAP }\end{array}$ & NMOSD & CSF & $\begin{array}{c}\text { MS patients }(\mathrm{N}=10) \\
\text { NMOSD patients }(\mathrm{N}=10) \\
\text { idiopathic longitudinally } \\
\text { extensive transverse myelitis } \\
\text { patients }(\mathrm{N}=12)\end{array}$ & 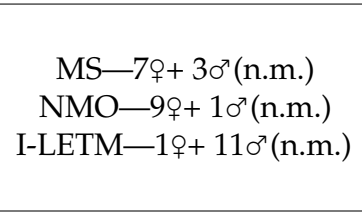 & $\begin{array}{c}18,000 \times g\left(30^{\prime}\right)+ \\
\text { ultracentrifugation }\end{array}$ & $\begin{array}{l}442 \text { significant proteins generated a list of } \\
\text { signature molecules of diseases validated } \\
\text { primarily by the identification of known } \\
\text { markers such as GFAP and FN1, specific to } \\
\text { NMO and MS. }\end{array}$ & [24] \\
\hline $\begin{array}{l}\text { KLKB1, } \\
\text { APOE }\end{array}$ & MS & CSF & $\begin{array}{l}\text { RRMS patients }(\mathrm{N}=4) \text {, } \\
\text { non-demyelinating controls } \\
(\mathrm{N}=3)\end{array}$ & n.m. & $\begin{array}{l}\text { Exo-Spin }{ }^{\mathrm{TM}} \text { (Cell } \\
\text { Guidance Systems) }\end{array}$ & $\begin{array}{l}\text { Plasma kallikrein and Apolipoprotein-E4 } \\
\text { were increased in CSF-EVs compared to } \\
\text { CSF. }\end{array}$ & [31] \\
\hline
\end{tabular}


Table 1. Cont.

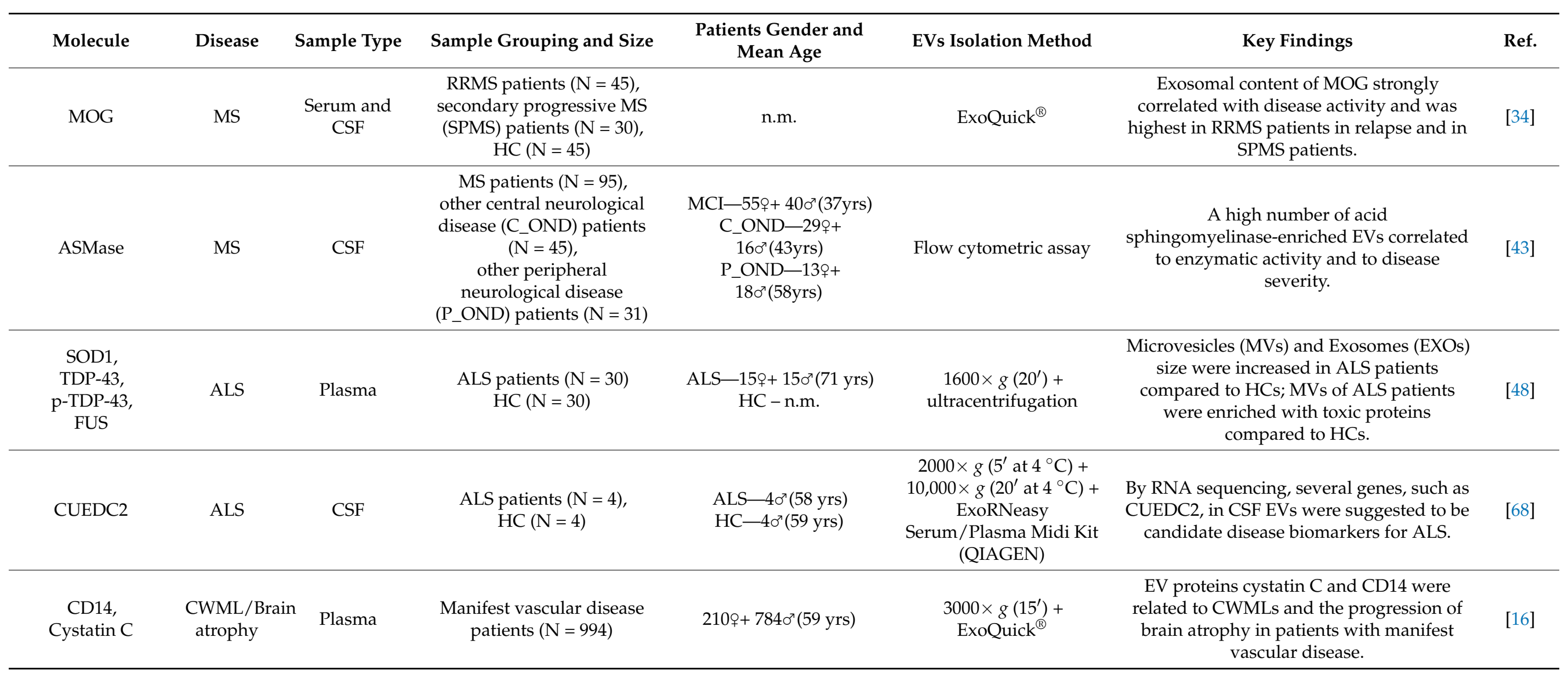


Table 1. Cont.

\begin{tabular}{|c|c|c|c|c|c|c|c|}
\hline Molecule & Disease & Sample Type & Sample Grouping and Size & $\begin{array}{c}\text { Patients Gender and } \\
\text { Mean Age }\end{array}$ & EVs Isolation Method & Key Findings & Ref. \\
\hline $\begin{array}{c}\text { Ras-related sma } \\
\text { GTPase 10, } \\
\text { Annexin VII, } \\
\text { UCHL1, } \\
\text { Claudin-5, } \\
\text { NKCC1, } \\
\text { AQP4, } \\
\text { SYNGR3, } \\
\text { A } 342, \\
\text { P-T181-tau, } \\
\text { P-S396-tau, } \\
\text { IL-6, } \\
\text { PRPc }\end{array}$ & TBI & Plasma & $\begin{array}{l}\text { Acute mild TBI }(\mathrm{N}=18) \\
\text { chronic mild TBI }(\mathrm{N}=14) \\
\text { HC }(\mathrm{N}=21)\end{array}$ & $\begin{array}{l}\text { Acute mild TBI-12ᄋ+ } \\
6 \sigma^{\top}(21 \text { yrs }) \\
\text { Chronic mild TBI-3 }+3+ \\
11 \sigma^{\top}(20 \text { yrs }) \\
\text { HC- }-14++7 \sigma^{7}(21 \mathrm{yrs})\end{array}$ & $\begin{array}{l}\text { Thromboplastin-D + } \\
3000 \times g\left(30^{\prime} \text { at } 4{ }^{\circ} \mathrm{C}\right)+ \\
\text { ExoQuick } \\
+ \text { L1CAM IP }\end{array}$ & $\begin{array}{l}\text { Increases in NDEV levels of most } \\
\text { neurofunctional proteins in acute mild TBI, } \\
\text { and elevations of most NDEV } \\
\text { neuropathological proteins in chronic and } \\
\text { acute mild TBI delineated phase-specificity. }\end{array}$ & [60] \\
\hline $\begin{array}{l}\text { FLOT1, } \\
\text { Arf6, } \\
\text { Rab7a }\end{array}$ & TBI & CSF & $\begin{array}{l}\text { Severe TBI patients }(\mathrm{N}=17) \\
\qquad \mathrm{HC}(\mathrm{N}=18)\end{array}$ & $\begin{array}{l}\text { Severe TBI-2o+ } \\
15 \sigma^{\top}(40 \text { yrs }) \\
\text { HC-n.m. }\end{array}$ & $\begin{array}{l}500 \times g\left(10^{\prime} \text { at } 4{ }^{\circ} \mathrm{C}\right)+ \\
2000 \times g\left(30^{\prime} \text { at } 4{ }^{\circ} \mathrm{C}\right)+ \\
\text { ultracentrifugation }\end{array}$ & $\begin{array}{l}\text { CSF after severe TBI contains Flotillin+ EVs. } \\
\text { Unfavorable outcomes included decreasing } \\
\text { Arf6 concentrations and a delayed Rab7a } \\
\text { concentration increase. }\end{array}$ & [64] \\
\hline $\begin{array}{l}\text { A } \beta 42, \\
\text { NRGN }\end{array}$ & TBI & Plasma & $\begin{array}{l}\text { Mild TBI patients }(\mathrm{N}=19) \\
\qquad \mathrm{HC}(\mathrm{N}=20)\end{array}$ & 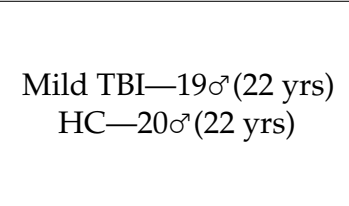 & $\begin{array}{c}\text { Thrombin }+10,000 \mathrm{rpm} \\
\left(5^{\prime}\right)+ \\
\text { ExoQuick }{ }^{\circledR}+\text { L1CAM or } \\
\text { GLAST IP }\end{array}$ & $\begin{array}{l}\text { NDEV and ADEV levels of A } \beta 42 \text { were } \\
\text { significantly higher while NDEV and } \\
\text { ADEV levels of neurogranin were } \\
\text { significantly lower in mild TBI patients } \\
\text { compared to HCs. }\end{array}$ & [74] \\
\hline $\begin{array}{c}\text { A } \beta 42, \\
\text { P-tau, } \\
\text { PRPc, } \\
\text { SYNGR3 }\end{array}$ & TBI & Plasma & $\begin{array}{c}\text { TBI patients: } \\
\text { W/CI }(\mathrm{N}=26) \\
\text { W/o CI }(\mathrm{N}=21) \\
\text { Controls: } \\
\text { W/CI }(\mathrm{N}=19) \\
\text { W/o CI }(\mathrm{N}=42)\end{array}$ & 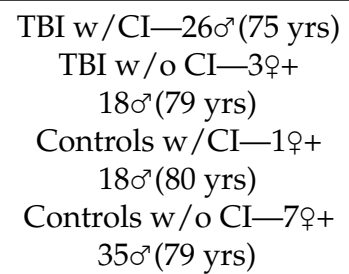 & $\begin{array}{l}\text { Thromboplastin-D + } \\
3000 \times g\left(30^{\prime} \text { at } 4^{\circ} \mathrm{C}\right)+ \\
\text { ExoQuick }{ }^{\circledR} \\
+ \text { L1CAM IP }\end{array}$ & $\begin{array}{l}\mathrm{A} \beta 42 \text { and P-tau species, and their } \\
\text { respective putative receptors, PrPc and } \\
\text { synaptogyrin-3, remain elevated for } \\
\text { decades after TBI, and may mediate } \\
\text { TBI-associated CI. }\end{array}$ & [81] \\
\hline
\end{tabular}


Table 1. Cont.

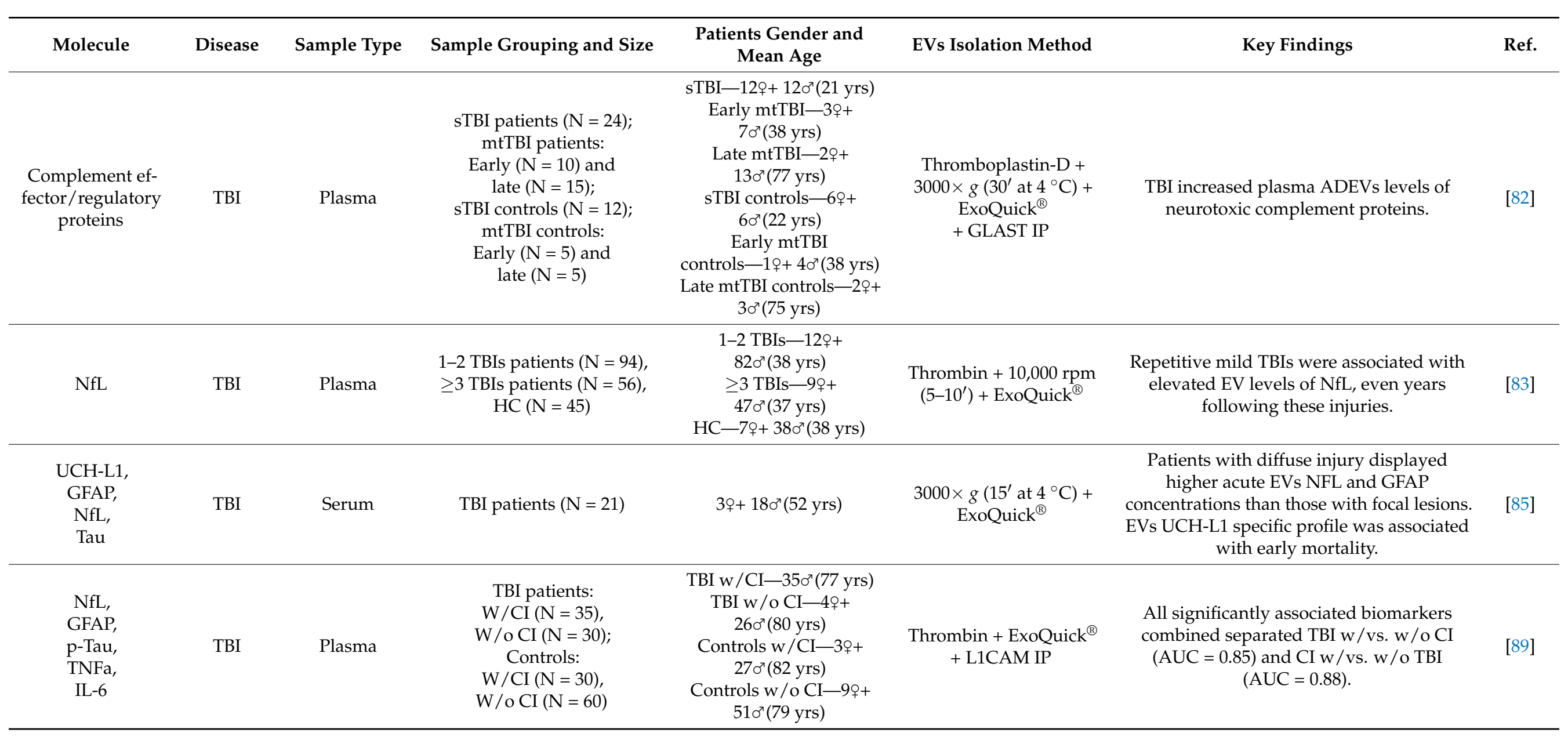


Table 1. Cont.

\begin{tabular}{|c|c|c|c|c|c|c|c|}
\hline Molecule & Disease & Sample Type & Sample Grouping and Size & $\begin{array}{c}\text { Patients Gender and } \\
\text { Mean Age }\end{array}$ & EVs Isolation Method & Key Findings & Ref. \\
\hline $\begin{array}{l}\text { ASC, } \\
\text { caspase-1, } \\
\text { IL-1 } 1 \beta \\
\text { IL-18 }\end{array}$ & Stroke & Serum & $\begin{array}{l}\text { Patients }(\mathrm{N}=16), \\
\mathrm{HC}(\mathrm{N}=80)\end{array}$ & $\begin{array}{c}\text { Stroke-n.m. } \\
\mathrm{HC}-40 \rho+400^{\top}(\mathrm{n} . \mathrm{m} .)\end{array}$ & $\begin{array}{c}2000 \times g\left(30^{\prime}\right)+ \\
\text { Total Exosome Isolation } \\
\text { reagent/ } \\
3000 \times g\left(15^{\prime}\right)+ \\
\text { ExoQuick }^{\circledR}\end{array}$ & $\begin{array}{l}\text { The AUC for ASC was } 0.99 \text {, whereas the } \\
\text { AUC for caspase- } 1 \text {, IL- } 1 \beta \text {, and IL- } 18 \text { were } \\
0.75,0.61 \text {, and } 0.67 \text {, respectively, and can act } \\
\text { as biomarkers for stroke. }\end{array}$ & [38] \\
\hline $\begin{array}{c}\text { Tau, } \\
\text { p-tau181 }\end{array}$ & $\begin{array}{l}\text { Chronic } \\
\text { traumatic } \\
\text { en- } \\
\text { cephalopa- } \\
\text { thy }\end{array}$ & CSF & $\begin{array}{l}\text { Patients }(\mathrm{N}=15) \\
\text { HC }(\mathrm{N}=16)\end{array}$ & 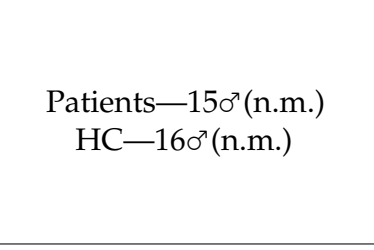 & $\begin{array}{c}1200 \times g\left(20^{\prime} \text { at } 4^{\circ} \mathrm{C}\right)+ \\
10,000 \times g\left(30^{\prime} \text { at } 4^{\circ} \mathrm{C}\right)+ \\
\text { MagCapture }{ }^{\mathrm{TM}} \text { Exosome } \\
\text { Isolation Kit PS } \\
\text { (FUJIFILM Wako Pure } \\
\text { Chemical Corporation) }\end{array}$ & $\begin{array}{l}\text { T-tau and p-tau181 levels of CSF-derived } \\
\text { EV were positively correlated with the t-tau } \\
\text { and p-tau181 levels of total CSF in patients, } \\
\text { respectively, but not in the HCs. }\end{array}$ & [67] \\
\hline $\begin{array}{l}\text { TLN1, } \\
\text { FLNA, } \\
14-3-3 \text { proteins }\end{array}$ & $\mathrm{ME} / \mathrm{CFS}$ & Plasma & $\begin{array}{l}\text { ME/CFS patients }(\mathrm{N}=99) \\
\text { ICF patients }(\mathrm{N}=6) \\
\text { depression patients }(\mathrm{N}=8) \\
\quad \mathrm{HC}(\mathrm{N}=56)\end{array}$ & n.m. & SEC (qEV iZON Science) & $\begin{array}{l}\text { Talin-1, filamin-A, and 14-3-3 family } \\
\text { proteins were the most abundant proteins } \\
\text { in EVs from ME/CFS patients. }\end{array}$ & [80] \\
\hline $\begin{array}{l}\text { S100a9, } \\
\text { S100a7, } \\
\text { lTF, } \\
\text { DEFA1 }\end{array}$ & $\mathrm{ABE}$ & CSF & $\begin{array}{l}\text { Moderate ABE patients } \\
(\mathrm{N}=10), \\
\text { severe ABE patients }(\mathrm{N}=10), \\
\mathrm{HC}(\mathrm{N}=10)\end{array}$ & $\begin{array}{c}\text { Moderate ABE-4+ } \\
60^{\top}(5.7 \text { days }) \\
\text { Severe ABE-3 }-3+7 \sigma^{\top}(5.5 \\
\text { days }) \\
\text { HC- }-5 q+50^{\top}(6.4 \text { days })\end{array}$ & $\begin{array}{l}2000 \times g\left(20^{\prime} \text { at } 4^{\circ} \mathrm{C}\right)+ \\
\text { Ribo }^{\mathrm{TM}} \text { exosome isolation } \\
\text { reagent }\end{array}$ & $\begin{array}{l}\text { A total of } 291 \text { dysregulated proteins were } \\
\text { identified by comparing ABE patients with } \\
\text { HCs, by mass spectrometry. S100a9, S100a7, } \\
\text { lTF and DEFA1 were further validated. }\end{array}$ & [95] \\
\hline $\begin{array}{l}\alpha \text {-synuclein, } \\
\text { IL-1 } \beta\end{array}$ & $\begin{array}{l}\text { Epilepsy } \\
\text { and ADD }\end{array}$ & Serum & $\begin{array}{l}\text { Epilepsy patients }(\mathrm{N}=115) \\
\text { ADD patients }(\mathrm{N}=10) \\
\text { HC }(\mathrm{N}=146)\end{array}$ & $\begin{array}{c}\text { Epilepsy-47o+ } \\
680^{7}(9 \text { yrs }) \\
\text { ADD-7o+3 }+3 \sigma^{7}(8 \text { yrs }) \\
\text { HC-68o+ } 760^{7}(9 \text { yrs })\end{array}$ & $\begin{array}{c}3000 \times g\left(15^{\prime} \text { at } 4^{\circ} \mathrm{C}\right)+ \\
\text { ExoQuick }^{\circledR}\end{array}$ & $\begin{array}{l}\alpha \text {-synuclein levels were significantly } \\
\text { increased in children with epilepsy and } \\
\text { with ADD of the CNS and correlated with } \\
\text { measures of disease severity. IL-1 } \beta \text { levels } \\
\text { showed significant correlation only with } \\
\text { drug resistance in children with epilepsy. }\end{array}$ & [77] \\
\hline $\begin{array}{l}\text { Phosphatidy- } \\
\text { lserine }\end{array}$ & SCZ & CSF & $\begin{array}{c}\text { SCZ patients }(\mathrm{N}=2) \\
\mathrm{HC}(\mathrm{N}=14)\end{array}$ & $\begin{array}{c}\text { SCZ-2o(56 yrs }) \\
\text { HC-n.m. }\end{array}$ & $\begin{array}{l}2000 \times g\left(20^{\prime} \text { at RT }\right)+ \\
13,000 \times g\left(2^{\prime} \text { at } \mathrm{RT}\right)+ \\
\text { flow cytometric assay }\end{array}$ & $\begin{array}{c}\text { SCZ patients displayed more } \\
\text { phosphatidylserine+ EVs in CSF compared } \\
\text { with HCs. }\end{array}$ & [15] \\
\hline
\end{tabular}


Table 1. Cont.

\begin{tabular}{|c|c|c|c|c|c|c|c|}
\hline Molecule & Disease & Sample Type & Sample Grouping and Size & $\begin{array}{c}\text { Patients Gender and } \\
\text { Mean Age }\end{array}$ & EVs Isolation Method & Key Findings & Ref. \\
\hline $\begin{array}{l}\text { IL-34, } \\
\text { SYP, } \\
\text { TNFR1 }\end{array}$ & MDD & Plasma & $\begin{array}{c}\text { MDD patients }(\mathrm{N}=34) \\
\text { HC }(\mathrm{N}=34)\end{array}$ & $\begin{array}{c}\text { MDD-14+ } 20 \sigma^{7}(31 \mathrm{yrs}) \\
\mathrm{HC}-14++20 \sigma^{7} \text { (n.m.) }\end{array}$ & $\begin{array}{c}\text { “Sandwich" ELISA } \\
\text { w/CD81 }\end{array}$ & $\begin{array}{l}\text { IL-34/CD81 levels were significantly higher } \\
\text { in MDD group compared to HC group. } \\
\text { Synaptophysin (SYP), SYP/CD81, and } \\
\text { TNFR1/CD81 were positively correlated } \\
\text { with severities of depression and/or } \\
\text { various subsymptoms. }\end{array}$ & [39] \\
\hline IRS-1 & MDD & Plasma & $\begin{array}{c}\text { MDD patients }(\mathrm{N}=64) \\
\text { HC }(\mathrm{N}=29)\end{array}$ & $\begin{array}{c}\text { MDD—40o+ }+240^{\top}(43 \mathrm{yrs}) \\
\mathrm{HC}-11 \%+180^{7} \\
(38 \mathrm{yrs})\end{array}$ & $\begin{array}{c}\text { Thrombin }+4500 \times g\left(20^{\prime}\right. \\
\left.\text { at }^{\circ}{ }^{\circ} \mathrm{C}\right)+ \text { ExoQuick } \\
\\
\text { L1CAM IP }\end{array}$ & $\begin{array}{l}\text { An increased concentration of IRS- } 1 \text { in EVs } \\
\text { of MDD patients was found, as compared } \\
\text { with HC. Gender differences were observed } \\
\text { for serine-312 phosphorylation of IRS- } 1 \text { in } \\
\text { MDD patients EVs. }\end{array}$ & [86] \\
\hline $\begin{array}{l}\text { TNFR1, } \\
\text { NF-кB }\end{array}$ & $\begin{array}{l}\text { Bipolar } \\
\text { disorder }\end{array}$ & Plasma & $\begin{array}{c}\text { Patients: } \\
\text { Infliximab-treated }(\mathrm{N}=27) \\
\text { placebo }(\mathrm{N}=28)\end{array}$ & $\begin{array}{l}\text { Infliximab-20+ } \\
7 \sigma^{\top}(44 \text { yrs }) \\
\text { Placebo-24+ }+ \\
4 \sigma^{\top}(46 \text { yrs })\end{array}$ & $\begin{array}{l}\text { Thrombin }+4500 \times g\left(20^{\prime}\right. \\
\left.\text { at } 4{ }^{\circ} \mathrm{C}\right)+ \text { ExoQuick } \\
+ \text { L1CAM IP }\end{array}$ & $\begin{array}{l}\text { Higher levels of physical abuse were } \\
\text { associated with larger biomarker decreases } \\
\text { over time. The antidepressant response to } \\
\text { infliximab was moderated by TNFR1. In } \\
\text { infliximab-treated participants, reductions } \\
\text { in TNFR1 levels were associated with } \\
\text { improvement in depressive symptoms. }\end{array}$ & [84] \\
\hline $\begin{array}{l}\text { MGMT, } \\
\text { APNG }\end{array}$ & GM & Serum & $\begin{array}{l}\text { GM patients }(\mathrm{N}=17) \\
\mathrm{HC}(\mathrm{N}=15)\end{array}$ & n.m. & $\begin{array}{c}1100 \times g\left(10^{\prime}\right)+ \\
\text { immunomagnetic } \\
\text { exosomal RNA (iMER) } \\
\text { platform }\end{array}$ & $\begin{array}{l}\text { EVs mRNA levels of MGMT and APNG } \\
\text { correlate well with levels found in parental } \\
\text { cells and change considerably during } \\
\text { treatment of seven GM patients. }\end{array}$ & [19] \\
\hline $\begin{array}{l}\text { EGFRvIII } \\
\text { mutation }\end{array}$ & GM & CSF & GM patients $(\mathrm{N}=71)$ & $200+51 \sigma^{\top}(61 \mathrm{yrs})$ & $\begin{array}{c}1500 \times g\left(10^{\prime}\right)+ \\
\text { ultracentrifugation }\end{array}$ & $\begin{array}{l}\text { EGFRvIII was detected in CSF-derived EVs } \\
\text { for } 14 / 23 \text { EGFRvIII tissue+ GM patients. } \\
\text { Only one of the } 48 \text { EGFRvIII tissue- patients } \\
\text { had the EGFRvIII mutation detected in EVs. } \\
\text { Sensitivity and specificity of EVs to detect } \\
\text { an EGFRvIII-positive GBM was } 61 \% \text { and } \\
98 \% \text {, respectively. }\end{array}$ & [28] \\
\hline
\end{tabular}


Table 1. Cont.

\begin{tabular}{|c|c|c|c|c|c|c|c|}
\hline Molecule & Disease & Sample Type & Sample Grouping and Size & $\begin{array}{c}\text { Patients Gender and } \\
\text { Mean Age }\end{array}$ & EVs Isolation Method & Key Findings & Ref. \\
\hline $\begin{array}{l}\text { EGFRvIII } \\
\text { mutation }\end{array}$ & GM & Serum/plasma & $\begin{array}{c}\text { GM patients }(\mathrm{N}=13) \\
\mathrm{HC}(\mathrm{N}=6)\end{array}$ & $\begin{array}{c}\mathrm{GM}-4 \text { 우 }+80^{\top}(63 \mathrm{yrs}) \\
\mathrm{HC}-\text { n.m. }\end{array}$ & Microfluidic isolation & $\begin{array}{l}\text { The }{ }^{\mathrm{EV}} \mathrm{HB}-\mathrm{Chip} \text { achieved } 94 \% \text { tumor-EV } \\
\text { specificity. EVs from serum and plasma } \\
\text { samples from GM patients had mutant } \\
\text { EGFRvIII mRNA. }\end{array}$ & [44] \\
\hline PD-L1 & GM & Serum/plasma & $\begin{array}{c}\text { GM patients }(\mathrm{N}=21) \\
\mathrm{HC}(\mathrm{N}=5)\end{array}$ & n.m. & $\begin{array}{c}15,000 \times g\left(10^{\prime}\right)+ \\
\text { ultracentrifugation }\end{array}$ & $\begin{array}{l}\text { PD-L1 DNA was present in circulating EVs } \\
\text { from GM patients where it correlated with } \\
\text { tumor volumes of up to } 60 \mathrm{~cm}^{3} .\end{array}$ & [45] \\
\hline $\begin{array}{l}\text { IFN- } \gamma, \\
\text { IL-10, } \\
\text { IL-3, } \\
\text { B7-1, } \\
\text { B7-2, } \\
\text { ICOSL }\end{array}$ & GM & Plasma & $\begin{array}{l}\text { GM patients }(\mathrm{N}=19) \\
\text { HC }(\mathrm{N}=19)\end{array}$ & $\begin{array}{c}\mathrm{GM}-69+130^{\top}(\mathrm{n} \cdot \mathrm{m} .) \\
\mathrm{HC}-\mathrm{n} \cdot \mathrm{m} .\end{array}$ & $\begin{array}{l}3000 \mathrm{rpm}^{\mathrm{TM}}\left(15^{\prime}\right)+ \\
\text { OptiPrep } \\
\text { (Solution } \\
\text { ultracentrifugation }+\end{array}$ & $\begin{array}{l}\text { Cytokines and costimulatory molecules } \\
\text { were readily detected but appeared globally } \\
\text { reduced in GM patients' EVs. }\end{array}$ & [57] \\
\hline $\begin{array}{l}\text { GFAP, } \\
\text { Tau }\end{array}$ & GM & Plasma & $\begin{array}{c}\text { GM patients }(\mathrm{N}=15) \\
\mathrm{HC}(\mathrm{N}=8)\end{array}$ & n.m. & $\begin{array}{l}\text { Dielectrophoretic (DEP) } \\
\text { micro-chip device }\end{array}$ & $\begin{array}{c}\text { For GM diagnosis, EV-GFAP reached } 93 \% \\
\text { sensitivity, } 38 \% \text { specificity, and AUC of } 0.65 ; \\
\text { for EV-Tau, } 67 \% \text { sensitivity, } 75 \% \text { specificity } \\
\text { and AUC of } 0.71 \text { was disclosed. }\end{array}$ & [66] \\
\hline PTRF & Glioma & Serum & Glioma patients $(\mathrm{N}=36)$ & n.m. & $\begin{array}{c}10,000 \times g\left(30^{\prime}\right)+ \\
\text { ultracentrifugation }\end{array}$ & $\begin{array}{l}\text { A positive correlation between tumor grade } \\
\text { and PTRF expression was found in both } \\
\text { tumor tissues and blood EVs from GM } \\
\text { patients. PTRF expression in exosomes } \\
\text { isolated from the sera of GM patients was } \\
\text { decreased after surgery. }\end{array}$ & [37] \\
\hline
\end{tabular}


Table 1. Cont.

\begin{tabular}{|c|c|c|c|c|c|c|c|}
\hline Molecule & Disease & Sample Type & Sample Grouping and Size & $\begin{array}{c}\text { Patients Gender and } \\
\text { Mean Age }\end{array}$ & EVs Isolation Method & Key Findings & Ref. \\
\hline $\begin{array}{l}\text { EGFRvIII } \\
\text { mutation }\end{array}$ & Glioma & Serum & $\begin{array}{l}\text { Grade III glioma patients } \\
\text { (N = 23), } \\
\text { Grade IV glioma patients } \\
\quad(\mathrm{N}=73) \\
\text { Other neurological diseases } \\
\text { patients }(\mathrm{N}=15) \\
\text { HC }(\mathrm{N}=50)\end{array}$ & $\begin{array}{l}\text { Grade III glioma-4ㅇ+ } \\
19 \sigma^{\top}(44 \text { yrs }) \\
\text { Grade IV glioma-25+ } \\
48 \sigma^{\top}(53 \text { yrs }) \\
\text { Controls-n.m. }\end{array}$ & $\begin{array}{c}600 \times g\left(10^{\prime}\right)+2000 \times g \\
\left(20^{\prime}\right)+10,000 \times g\left(20^{\prime}\right)+ \\
\text { Total Exosome Isolation } \\
\text { Kit }\end{array}$ & $\begin{array}{l}\text { Sensitivity and specificity of EVs EGFRvIII } \\
\text { detection assay in serum were } 81.58 \% \text { and } \\
79.31 \% \text {, respectively. EGFRvIII expression } \\
\text { either in EVs or tissue correlated with poor } \\
\text { survival. }\end{array}$ & [41] \\
\hline $\begin{array}{l}\text { EGFR, } \\
\text { NLGN3, } \\
\text { PTTG1 }\end{array}$ & Glioma & Serum & $\begin{array}{l}\text { Glioma patients }(\mathrm{N}=23) \\
\qquad \mathrm{HC}(\mathrm{N}=12)\end{array}$ & $\begin{array}{l}\text { Glioma-9o+ } 14 \sigma^{\top}(52 \mathrm{yrs}) \\
\mathrm{HC}-39+9 \sigma^{\top}(59 \mathrm{yrs})\end{array}$ & $\begin{array}{l}2000 \times g\left(15^{\prime}\right)+ \\
\text { ultracentrifugation }\end{array}$ & $\begin{array}{l}\text { Protein expression of EGFR in EVs can } \\
\text { accurately differentiate high-grade and } \\
\text { low-grade glioma patients, and positively } \\
\text { correlates with ki-67 labeling index in } \\
\text { tumor tissue. NLGN3 and PTTG1 mRNA } \\
\text { in EVs were also validated for detecting } \\
\text { glioma patients. }\end{array}$ & [73] \\
\hline FASN & Glioma & Plasma & $\begin{array}{c}\text { Glioma patients }(\mathrm{N}=8+9) \\
\mathrm{HC}(\mathrm{N}=8+3)\end{array}$ & n.m. & $\begin{array}{c}1000 \times g\left(7^{\prime}\right)+10,000 \times g \\
\left(30^{\prime}\right)+ \\
\text { ultracentrifugation }\end{array}$ & $\begin{array}{l}\text { FASN was elevated in CD63+ and CD81+ } \\
\text { EVs in glioma patient samples. }\end{array}$ & [92] \\
\hline $\begin{array}{l}\text { GFAP, } \\
\text { Survivin }\end{array}$ & Glioma & Serum & $\begin{array}{l}\text { Glioma patients }(\mathrm{N}=8) \\
\mathrm{HC}(\mathrm{N}=3)\end{array}$ & $\begin{array}{c}\text { Glioma-3o+5 } 5 \sigma^{\top}(52 \text { yrs }) \\
\text { HC-n.m. }\end{array}$ & $\begin{array}{l}10,000 \times g\left(80^{\prime} \text { at } 4^{\circ} \mathrm{C}\right)+ \\
\quad \text { ultracentrifugation }\end{array}$ & $\begin{array}{l}\text { Patients with longer time to tumor } \\
\text { progression exhibited a decrease in } \\
\text { CD9+/SVN+ and CD9+/GFAP+/SVN+ } \\
\text { EVs immediately following survivin } \\
\text { vaccination; whereas, those with early } \\
\text { tumor progression had an increase in the } \\
\text { same markers, despite anti-survivin } \\
\text { immunotherapy. }\end{array}$ & [97] \\
\hline
\end{tabular}


Table 1. Cont.

\begin{tabular}{|c|c|c|c|c|c|c|c|}
\hline Molecule & Disease & Sample Type & Sample Grouping and Size & $\begin{array}{c}\text { Patients Gender and } \\
\text { Mean Age }\end{array}$ & EVs Isolation Method & Key Findings & Ref. \\
\hline PpIX & Glioma & Plasma & Glioma patients $(\mathrm{N}=6)$ & $2 q+4 \circ^{\top}(59 \mathrm{yrs})$ & $\begin{array}{c}\text { exoEasy Maxi Kit } \\
\text { (Qiagen) }\end{array}$ & $\begin{array}{l}\text { Plasma of patients with avidly fluorescent } \\
\text { tumors undergoing FGS contain circulating } \\
\text { PpIX+ EVs at levels significantly higher } \\
\text { than their predosing background, which } \\
\text { correlates with enhancing tumor volumes. }\end{array}$ & [62] \\
\hline $\begin{array}{l}\text { CD63 } \\
\text { CD81 }\end{array}$ & $\begin{array}{l}\text { Brain } \\
\text { tumors } \\
\text { (mixed) }\end{array}$ & Plasma & $\begin{array}{c}\text { GM patients (n.m.), } \\
\text { anaplastic astrocytoma } \\
\text { patients (n.m.), } \\
\text { brain metastases patients } \\
\text { (n.m.), } \\
\text { meningioma patients (n.m), } \\
\text { Pituitary adenoma patients } \\
\text { (n.m.), } \\
\text { epilepsy controls (n.m.), } \\
\text { HC (n.m.) }\end{array}$ & n.m. & $\begin{array}{c}15,000 \times g\left(15^{\prime}\right)+ \\
\text { ultracentrifugation }\end{array}$ & $\begin{array}{l}\text { EVs with double positive CD63+/CD81+ } \\
\text { expression are enriched in cancer cell lines } \\
\text { and patient plasma samples. }\end{array}$ & [69] \\
\hline
\end{tabular}

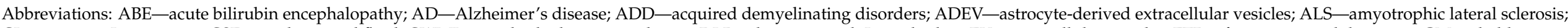

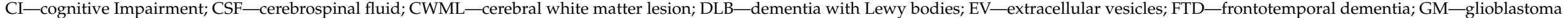

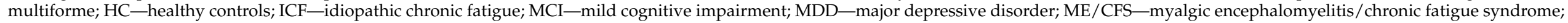

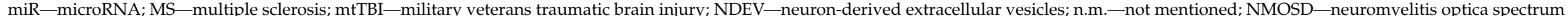

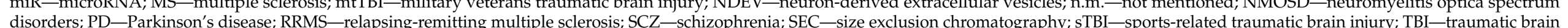
injury; yrs-years. 
Table 2. Extracellular vesicles non-coding RNAs as biomarkers associated with central nervous system pathological conditions.

\begin{tabular}{|c|c|c|c|c|c|c|c|}
\hline Molecule & Disease & Sample Type & Sample Grouping and Size & $\begin{array}{c}\text { Patients Gender and } \\
\text { Mean Age }\end{array}$ & EVs Isolation Method & Key Findings & Ref. \\
\hline $\begin{array}{l}\text { miR-16-5p, } \\
\text { miR-125b-5p, } \\
\text { miR-451a, } \\
\text { miR-605-5p }\end{array}$ & $\mathrm{AD}$ & CSF & $\begin{array}{c}\text { Young-onset AD (YOAD) } \\
\text { Patients }(\mathrm{N}=17) \\
\text { Late-onset AD (LOAD) } \\
\text { Patients }(\mathrm{N}=13) \\
\mathrm{HC}(\mathrm{N}=12)\end{array}$ & $\begin{array}{c}\text { YOAD-10+ }+7 \sigma^{7}(61 \mathrm{yrs}) \\
\text { LOAD-5+ }+8 \sigma^{\top}(76 \mathrm{yrs}) \\
\mathrm{HC}-7+9+5 \sigma^{\top}(67 \mathrm{yrs})\end{array}$ & $\begin{array}{l}\quad 3000 \times g\left(5^{\prime}\right)+ \\
\text { miRCURY } Y^{\mathrm{TM}} \text { Exosome } \\
\text { Isolation Kit (Exiqon) }\end{array}$ & $\begin{array}{l}\text { MiR-16-5p, miR- } 125 b-5 p, \text { miR-451a, and } \\
\text { miR-605-5p were differentially expressed in } \\
\text { the EVs of YOAD patients when compared } \\
\text { with HC. In LOAD patients, miR-125b-5p, } \\
\text { miR-451a, and miR-605-5p were similarly } \\
\text { altered in expression, but miR-16-5p } \\
\text { showed similar expression to HC. }\end{array}$ & [42] \\
\hline $\begin{array}{c}\text { miR-27a-3p, } \\
\text { miR-30a-5p, } \\
\text { miR-34c, } \\
\text { piR_019324, } \\
\text { piR_019949, } \\
\text { piR_020364 }\end{array}$ & $\mathrm{AD}$ & CSF & $\begin{array}{c}\text { AD patients }(\mathrm{N}=42), \\
\text { MCI patients }(\mathrm{N}=17) \\
\text { psychiatric and neurological } \\
\text { controls }(\mathrm{N}=82)\end{array}$ & n.m. & $\begin{array}{l}3500 \times g\left(10^{\prime} \text { at } 4^{\circ} \mathrm{C}\right)+ \\
2 \times 4500 \times g\left(10^{\prime} \text { at } 4^{\circ} \mathrm{C}\right)+ \\
10,000 \times g\left(30^{\prime} \text { at } 4^{\circ} \mathrm{C}\right)+ \\
\text { ultracentrifugation }\end{array}$ & $\begin{array}{l}\text { A combined signature consisting of three } \\
\text { miRNAs and three piRNAs were suitable to } \\
\text { detect AD with an AUC of } 0.83 \text {. The piRNA } \\
\text { signature could predict the conversion of } \\
\text { MCI patients to AD with an AUC of } 0.86 \text {. } \\
\text { When combining the smallRNA signature } \\
\text { with pTau and A } \beta 42 / 40 \text { ratio the AUC } \\
\text { reaches } 0.98 \text {. }\end{array}$ & [61] \\
\hline $\begin{array}{l}\text { miR-23a-3p, } \\
\text { miR-223-3p, } \\
\text { miR-190a-5p, } \\
\text { miR-100-3p }\end{array}$ & $\mathrm{AD}$ & Plasma & $\begin{array}{c}\text { AD patients }(\mathrm{N}=40) \\
\mathrm{HC}(\mathrm{N}=40)\end{array}$ & $\begin{array}{l}\mathrm{AD}-25 \%+15 \sigma^{7} \\
(73 \mathrm{yrs}) \\
\mathrm{HC}-18 \%+22 \sigma^{7} \\
(67 \mathrm{yrs})\end{array}$ & $\begin{array}{c}3000 \times g\left(15^{\prime}\right)+ \\
\text { Thrombin }+10,000 \mathrm{rpm} \\
\left(5^{\prime}\right)+\text { ExoQuick } \\
\text { (System Biosciences) }^{\circledR} \\
+ \text { L1CAM IP }\end{array}$ & $\begin{array}{l}\text { MiR-23a-3p, miR-223-3p and miR-190a-5p } \\
\text { levels in NDEVs from AD patients were } \\
\text { significantly upregulated as compared with } \\
\text { HCs, whereas miR-100-3p levels were } \\
\text { significantly downregulated. }\end{array}$ & [93] \\
\hline $\begin{array}{l}\text { miR-204-5p, } \\
\text { miR-632 }\end{array}$ & FTD & $\mathrm{CSF}$ & $\begin{array}{c}\text { GeNFI cohort: } \\
\text { GRN, C9orf72 and MAPT } \\
\text { mutation carriers }(\mathrm{N}=38), \\
\text { Non-mutation carriers } \\
(\mathrm{N}=11) ; \\
\text { Sporadic disease cohort: } \\
\text { FTD patients }(\mathrm{N}=11), \\
\text { PPA patients }(\mathrm{N}=6) \\
\text { AD patients }(\mathrm{N}=13) \\
\text { HC }(\mathrm{N}=10)\end{array}$ & $\begin{array}{c}\text { Mutation carriers-25\%+ } \\
13 \sigma^{\top}(54 \mathrm{yrs}) \\
\text { Non-mutation } \\
\text { carriers-6 } 6+5 \sigma^{\top}(47 \mathrm{yrs}) \\
\text { FTD-2 }+9 \sigma^{\top}(67 \mathrm{yrs}) \\
\text { PPA-2 } 2+4 \sigma^{\top}(66 \mathrm{yrs}) \\
\text { AD- } 5++8 \sigma^{\top}(63 \mathrm{yrs}) \\
\text { HC-5 }+5 \sigma^{\top}(69 \mathrm{yrs})\end{array}$ & $\begin{array}{c}10,000 \times g\left(5^{\prime}\right)+ \\
\text { miRCURY }{ }^{\mathrm{TM}} \text { Exosome } \\
\text { Isolation Kit }\end{array}$ & $\begin{array}{l}\text { In the GeNFI cohort, miR-204-5p and } \\
\text { miR-632 were significantly decreased in } \\
\text { symptomatic compared with } \\
\text { presymptomatic mutation carriers, with an } \\
\text { AUC of } 0.89 \text { and } 0.81 \text {, respectively, } \\
\text { and } 0.93 \text { when combined. In sporadic FTD, } \\
\text { only miR- } 632 \text { was significantly decreased } \\
\text { compared with AD and HC (AUC }=0.90 \text { ). }\end{array}$ & [47] \\
\hline
\end{tabular}


Table 2. Cont.

\begin{tabular}{|c|c|c|c|c|c|c|c|}
\hline Molecule & Disease & Sample Type & Sample Grouping and Size & $\begin{array}{c}\text { Patients Gender and } \\
\text { Mean Age }\end{array}$ & EVs Isolation Method & Key Findings & Ref. \\
\hline $\mathrm{miR}-233$ & Dementia & Serum & $\begin{array}{l}\text { Dementia patients: } \\
\text { First clinic visit AD (ADfirst) } \\
(\mathrm{N}=11) \\
\text { Treatment-receiving AD } \\
\text { (ADcare) }(\mathrm{N}=11) \\
\text { VD }(\mathrm{N}=10) \\
\text { HC }(\mathrm{N}=16)\end{array}$ & 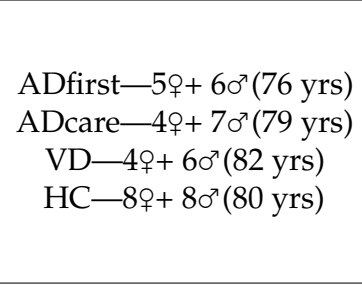 & $\begin{array}{c}3000 \times g\left(15^{\prime} \text { at } 4^{\circ} \mathrm{C}\right)+ \\
\text { ExoQuick }\end{array}$ & $\begin{array}{l}\text { The median levels of EVs miR-223 was } \\
\text { significantly decreased in dementia } \\
\text { patients, when comparing with HC } \\
\text { (AUC }=0.875)\end{array}$ & [51] \\
\hline $\begin{array}{l}\operatorname{miR}-132-3 p \\
\text { miR-212 }\end{array}$ & $\begin{array}{l}\mathrm{AD} \text { and } \\
\mathrm{MCI}\end{array}$ & Plasma & $\begin{array}{c}\text { AD patients }(\mathrm{N}=16) \\
\text { AD-MCI patients }(\mathrm{N}=16) \\
\text { HC }(\mathrm{N}=31)\end{array}$ & n.m. & $\begin{array}{c}\text { Thrombin }+6000 \times g\left(20^{\prime}\right. \\
\left.\text { at } 4{ }^{\circ} \mathrm{C}\right)+ \text { ExoQuick }{ }^{\circledR}+ \\
\text { L1CAM IP }\end{array}$ & $\begin{array}{l}\text { Measurement of miR-132-3p in NDEVs } \\
\text { showed good sensitivity and specificity to } \\
\text { diagnose AD, but did not effectively } \\
\text { separate individuals with AD-MCI from } \\
\text { HC. MiR-212 was also decreased in NDEVs } \\
\text { from AD patients compared to HC. }\end{array}$ & [55] \\
\hline $\begin{array}{c}\text { let-7e-5p, } \\
\text { miR- } 125 a-5 p \\
\text { miR-23a-3p, } \\
\text { miR-375, } \\
\text { miR-1468-5p, } \\
\text { miR-204-5p, } \\
\text { miR-369-5p, } \\
\text { miR-423-5p }\end{array}$ & $\begin{array}{l}\mathrm{AD} \text { and } \\
\mathrm{PD}\end{array}$ & Plasma & $\begin{array}{l}\text { AD patients }(\mathrm{N}=5) \\
\text { PD patients }(\mathrm{N}=7) \\
\text { HC }(\mathrm{N}=34)\end{array}$ & $\begin{array}{c}\mathrm{AD}-18 \%+22 \sigma^{7} \\
(67 \mathrm{yrs}) \\
\mathrm{PD}-6 \%+1 \sigma^{7}(62 \mathrm{yrs}) \\
\mathrm{HC}-14++20 \sigma^{7} \\
(33 \mathrm{yrs})\end{array}$ & $\begin{array}{c}\text { exoRNeasy } \\
\text { Serum/Plasma Maxi Kit } \\
(\text { QIAGEN) and } \\
8000 \times g\left(5^{\prime}\right)+ \\
\text { ExoQuick }^{\circledR}\end{array}$ & $\begin{array}{l}\text { Compared to the HC, eight miRNAs were } \\
\text { found to be significantly elevated/declined } \\
\text { in AD and PD samples, of which fiour } \\
\text { miRNAs were newly identified. }\end{array}$ & [87] \\
\hline $\begin{array}{c}\text { miR-1246, } \\
\text { miR-127-3p, } \\
\text { miR-19b-3p, } \\
\text { miR-134-5p, } \\
\text { miR-370-3p, } \\
\text { miR-375, } \\
\text { miR-379-5p, } \\
\text { miR-382-5p, } \\
\text { miR-432-5p, } \\
\text { miR-485-5p, } \\
\text { miR-493-3p }\end{array}$ & MS & Serum & RRMS patients $(\mathrm{N}=29)$ & $17 q+12 \sigma^{\top}(34 \mathrm{yrs})$ & SEC (qEV iZON Science) & $\begin{array}{l}\text { Several combinations of two or three } \\
\text { miRNAs were able to distinguish active } \\
\text { from quiescent disease with greater than } \\
90 \% \text { accuracy. Additional miRNAs } \\
\text { associated with stable remission, and a } \\
\text { positive response to fingolimod in patients } \\
\text { with active disease prior to treatment. }\end{array}$ & [79] \\
\hline
\end{tabular}


Table 2. Cont.

\begin{tabular}{|c|c|c|c|c|c|c|c|}
\hline Molecule & Disease & Sample Type & Sample Grouping and Size & $\begin{array}{c}\text { Patients Gender and } \\
\text { Mean Age }\end{array}$ & EVs Isolation Method & Key Findings & Ref. \\
\hline $\begin{array}{l}\text { miR-9-5p, } \\
\text { miR-15a-5p, } \\
\text { miR-183-5p } \\
\text { miR- 193a-5p, } \\
\text { miR-338-3p, } \\
\text { miR-1246 }\end{array}$ & ALS & Plasma & $\begin{array}{l}\text { ALS patients }(\mathrm{N}=14) \\
\mathrm{HC}(\mathrm{N}=8)\end{array}$ & $\begin{array}{c}\text { ALS-8o+6o }(62 \text { yrs }) \\
\text { HC-n.m. }\end{array}$ & Vn96 peptide method & $\begin{array}{l}\text { MiRNAs with relevance to ALS were found } \\
\text { to be deregulated, including miR-9-5p, } \\
\text { miR-183-5p, miR-338-3p and miR-1246. } \\
\text { MiR-15a-5p and miR-193a-5p were } \\
\text { identified for their di- agnostic potential of } \\
\text { ALS and association with disability } \\
\text { progression, respectively. }\end{array}$ & [70] \\
\hline $\begin{array}{l}\text { miR-146a-5p, } \\
\text { miR-199a-3p, } \\
\text { miR-4454, } \\
\text { miR-10b-5p, } \\
\text { miR-29b-3p, } \\
\text { miR-151a-3p, } \\
\text { miR-151a-5p, } \\
\text { miR-199a-5p }\end{array}$ & ALS/MND & Plasma & $\begin{array}{c}\text { ALS/MND patients }(\mathrm{N}=10 \\
+10) \\
\mathrm{HC}(\mathrm{N}=10+10)\end{array}$ & n.m. & $\begin{array}{l}\text { Thrombin + ExoQuick }{ }^{\circledR}+ \\
\text { L1CAM IP }\end{array}$ & $\begin{array}{l}\text { Five upregulated and three downregulated } \\
\text { miRNA sequences significantly } \\
\text { distinguished ALS/MND patients from HC } \\
\text { in two independent patient cohorts. }\end{array}$ & [75] \\
\hline $\begin{array}{l}\text { miR-203b-5p, } \\
\text { miR-203a-3p, } \\
\text { miR-206, } \\
\text { miR- 185-5p }\end{array}$ & TBI & Plasma & $\begin{array}{l}\text { TBI patients }(\mathrm{N}=16) \\
\mathrm{HC}(\mathrm{N}=20)\end{array}$ & n.m. & $\begin{array}{l}\text { Track Etched Magnetic } \\
\text { Nanopore (TENPO) } \\
\text { sorting for GluR2 }\end{array}$ & $\begin{array}{l}\text { A panel of four miRNAs significantly } \\
\text { discriminated TBI patients vs. HC. }\end{array}$ & [63] \\
\hline $\begin{array}{l}\operatorname{miR}-139-5 p \\
\text { miR-18a-5p, } \\
\text { miR-103a-3p }\end{array}$ & TBI & Plasma & $\begin{array}{l}\text { 1-2 TBIs patients }(\mathrm{N}=73) \\
\text { rTBI patients }(\mathrm{N}=45) \\
\mathrm{HC}(\mathrm{N}=35)\end{array}$ & 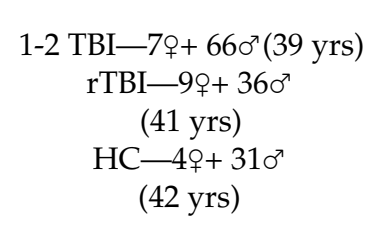 & $\begin{array}{c}3000 \mathrm{rpm}\left(5^{\prime}\right)+ \\
\text { exoRNeasy } \\
\text { Serum/Plasma Kit }\end{array}$ & $\begin{array}{l}\text { MiR-139-5p and miR-18a-5p, were } \\
\text { significantly differentially expressed in the } \\
\text { rTBI and 1-2 TBI groups. TBI history and } \\
\text { neurobehavioral symptom survey scores } \\
\text { negatively correlated with miR-103a-3p } \\
\text { expression. }\end{array}$ & [78] \\
\hline $\begin{array}{l}\text { miR-9, } \\
\text { miR-124 }\end{array}$ & AIS & Serum & $\begin{array}{l}\text { AIS patients }(\mathrm{N}=65) \\
\qquad \mathrm{HC}(\mathrm{N}=66)\end{array}$ & $\begin{array}{l}\text { AIS }-25 \%+400^{7} \\
\quad(64 \text { yrs }) \\
\text { HC }-30 \%+360^{7} \\
(60 \mathrm{yrs})\end{array}$ & $\begin{array}{c}21,000 \times g\left(15^{\prime} \text { at } 4^{\circ} \mathrm{C}\right)+ \\
\text { ExoQuick }^{\circledR}\end{array}$ & $\begin{array}{l}\text { miR-9 and miR-124 were significantly } \\
\text { higher in AIS patients vs. HC (AUCs of } \\
0.8026 \text { and } 0.6976 \text {, respectively). }\end{array}$ & [23] \\
\hline
\end{tabular}


Table 2. Cont.

\begin{tabular}{|c|c|c|c|c|c|c|c|}
\hline Molecule & Disease & Sample Type & Sample Grouping and Size & $\begin{array}{c}\text { Patients Gender and } \\
\text { Mean Age }\end{array}$ & EVs Isolation Method & Key Findings & Ref. \\
\hline $\begin{array}{l}\operatorname{miR}-21-5 p \\
\operatorname{miR}-30 a-5 p\end{array}$ & IS & Plasma & $\begin{array}{l}\text { HIS patients }(\mathrm{N}=15), \\
\text { AIS patients days } 1-3 \\
\quad(\mathrm{~N}=33), \\
\text { AIS patients days 3-7 } \\
\quad(\mathrm{N}=32), \\
\text { SIS patients }(\mathrm{N}=31), \\
\text { RIS patients }(\mathrm{N}=32) \\
\text { HC }(\mathrm{N}=24)\end{array}$ & 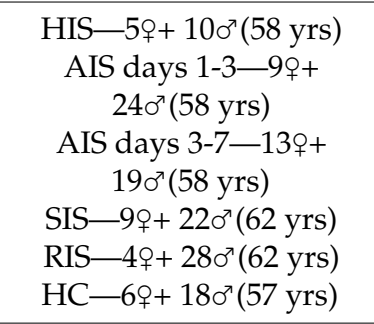 & $\begin{array}{c}16,000 \times g\left(10^{\prime} \text { at } 4{ }^{\circ} \mathrm{C}\right)+ \\
\text { exoRNeasy } \\
\text { Serum/Plasma Kit }\end{array}$ & $\begin{array}{l}\text { MiR- 21-5p and miRNA-30a-5p in } \\
\text { combination are promising biomarkers for } \\
\text { diagnosing IS and distinguishing among } \\
\text { HIS, SIS, and RIS, especially miRNA-30a-5p } \\
\text { for the diagnosis of the HIS phase. }\end{array}$ & [50] \\
\hline $\begin{array}{l}\operatorname{miR}-122-3 p \\
\operatorname{miR}-200 a-5 p\end{array}$ & NMOSD & Serum & $\begin{array}{l}\text { NMOSD in relapsing } \\
\text { patients }(\mathrm{N}=16) \\
\text { NMOSD in remission } \\
\text { patients }(\mathrm{N}=15) \\
\mathrm{HC}(\mathrm{N}=14)\end{array}$ & $\begin{array}{l}\text { NMOSD relapsing-14\%+ } \\
2 \sigma^{\top}(37 \mathrm{yrs}) \\
\text { NMOSD } \\
\text { remission-13\%+ } \\
2 \sigma^{\top}(39 \mathrm{yrs}) \\
\mathrm{HC}-12++2 \sigma^{\top}(35 \mathrm{yrs})\end{array}$ & $\begin{array}{l}\text { Ribo }^{\mathrm{TM}} \text { Exosome } \\
\text { Isolation Reagent } \\
\text { (RiboBio) }\end{array}$ & $\begin{array}{l}\text { MiR-122-3p and miR-200a-5p could } \\
\text { distinguish NMOSD status, and were } \\
\text { significantly upregulated in the serum EVs } \\
\text { of relapsing NMOSD compared with that in } \\
\text { remitting NMOSD. The two miRNAs had } \\
\text { positive correlations with disease severity } \\
\text { in NMOSD patients. }\end{array}$ & [76] \\
\hline $\begin{array}{c}\text { miR-3613-5p, } \\
\text { miR-4668-5p, } \\
\text { miR-8071, } \\
\text { miR-197-5p, } \\
\text { miR-4322, } \\
\text { miR-6781-5p }\end{array}$ & mTLE-HS & Plasma & $\begin{array}{c}\text { mTLE-HS patients }(\mathrm{N}=40) \\
\text { HC }(\mathrm{N}=40)\end{array}$ & $\begin{array}{c}\text { mTLE-HS-15o+ } \\
25 \sigma^{\top}(27 \text { yrs }) \\
\text { HC-n.m. }\end{array}$ & $\begin{array}{c}2000 \times g\left(20^{\prime}\right)+10,000 \times \\
g\left(20^{\prime}\right)+\text { ExoQuick }^{\circledR}\end{array}$ & $\begin{array}{l}\text { Among six candidate microRNAs, } \\
\text { miR- } 8071 \text { had the best diagnostic value for } \\
\text { mTLE-HS with } 83.33 \% \text { sensitivity and } \\
96.67 \% \text { specificity, and was associated with } \\
\text { seizure severity. }\end{array}$ & [32] \\
\hline $\begin{array}{c}\text { miR-206, } \\
\text { miR619-5p, } \\
\text { miR-133a-3p, } \\
\text { miR-143-3p, } \\
\text { miR-144-5p, } \\
\text { miR-499a-5p, } \\
\text { miR-3614-5p, } \\
\text { miR-941, } \\
\text { miR-30c-5p, } \\
\text { miR-339-5p, } \\
\text { miR-30b-5p, } \\
\text { miR-6515-5p }\end{array}$ & SCZ & Serum & $\begin{array}{l}\text { SCZ patients }(\mathrm{N}=100) \\
\mathrm{HC}(\mathrm{N}=100)\end{array}$ & $\begin{array}{l}\mathrm{SCZ}-50 \%+500^{7} \\
(30 \mathrm{yrs}) \\
\mathrm{HC}-42 \mathrm{q}+580^{7} \\
(29 \mathrm{yrs})\end{array}$ & SEC (qEV iZON Science) & $\begin{array}{c}\text { MiR-206 was the most upregulated miRNA } \\
\text { in the EVs of SCZ patients. A signature of } \\
11 \text { miRNAs were identified in EVs from } \\
\text { SCZ patients and were used to classify } \\
\text { samples from SCZ and HC subjects with } \\
\text { high accuracy. }\end{array}$ & [58] \\
\hline
\end{tabular}


Table 2. Cont.

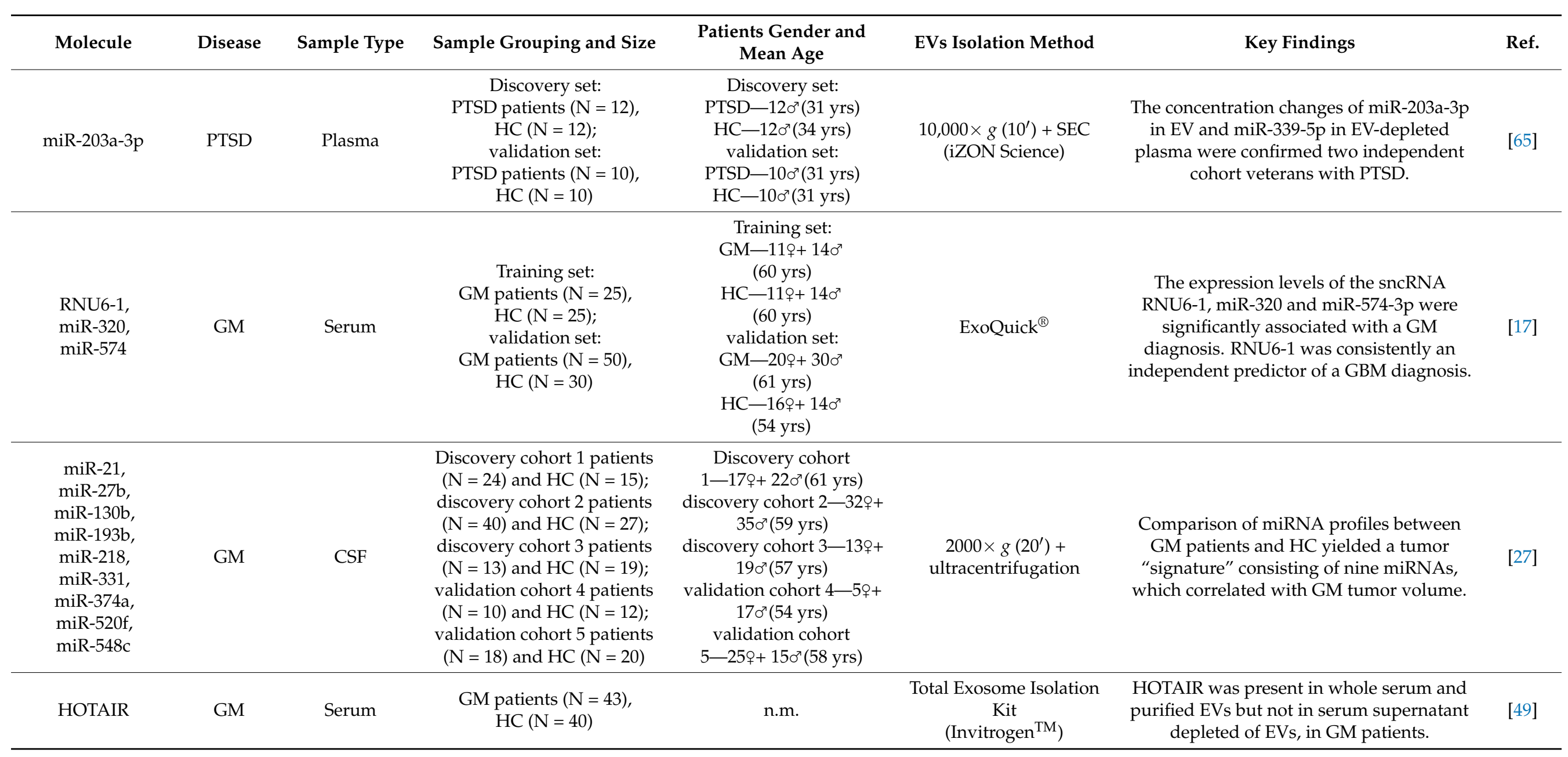


Table 2. Cont.

\begin{tabular}{|c|c|c|c|c|c|c|c|}
\hline Molecule & Disease & Sample Type & Sample Grouping and Size & $\begin{array}{l}\text { Patients Gender and } \\
\text { Mean Age }\end{array}$ & EVs Isolation Method & Key Findings & Ref. \\
\hline RNU6-1 & GM & Serum & $\begin{array}{c}\text { GM patients }(\mathrm{N}=18), \\
\text { subacute stroke patients } \\
(\mathrm{N}=30), \text { acute/subacute } \\
\text { hemorrhage patients } \\
(\mathrm{N}=30) \\
\text { MS patients }(\mathrm{N}=18), \\
\text { brain metastases patients } \\
(\mathrm{N}=21), \text { PCNSL patients } \\
(\mathrm{N}=12) \\
\text { HC }(\mathrm{n}=30)\end{array}$ & 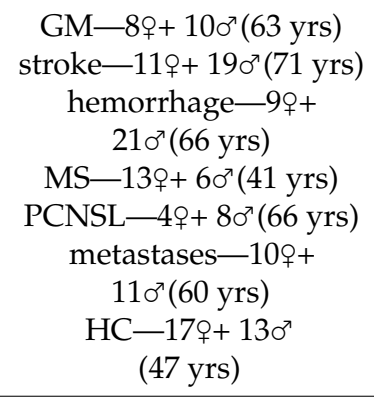 & ExoQuick $^{\circledR}$ & $\begin{array}{l}\text { RNU6-1 expression was significantly higher } \\
\text { in GM patients vs. HC, and also when } \\
\text { comparing with patients with } \\
\text { non-neoplastic lesions. No significant } \\
\text { differences were found between GM } \\
\text { patients and brain metastases. }\end{array}$ & [91] \\
\hline miR-21 & Glioma & CSF & $\begin{array}{c}\text { Glioma patients }(\mathrm{N}=70) \\
\text { non-glioma controls }(\mathrm{N}=25)\end{array}$ & $\begin{array}{l}\text { Glioma-28+ } \\
42 \sigma^{\top}(50 \mathrm{yrs}) \\
\text { non-glioma-7@+ } \\
180^{\top}(54 \mathrm{yrs})\end{array}$ & $\begin{array}{c}2000 \times g\left(30^{\prime}\right)+12,000 \times \\
g\left(25^{\prime}\right)+ \\
\text { ultracentrifugation }\end{array}$ & $\begin{array}{l}\text { MiR-21 levels in CSF-EVs of glioma patients } \\
\text { were found significantly higher than in } \\
\text { non-glioma controls; whereas no difference } \\
\text { was detected in serum-derived EVs. The } \\
\text { CSF-EVs miR-21 levels correlated with } \\
\text { tumor spinal/ventricle metastasis and the } \\
\text { recurrence with anatomical site preference. }\end{array}$ & [20] \\
\hline $\begin{array}{l}\text { miR-4443, } \\
\text { miR-422a, } \\
\text { miR-494-3p, } \\
\text { miR-502-5p, } \\
\text { miR-520f-3p, } \\
\text { miR-549a }\end{array}$ & Glioma & Serum & $\begin{array}{c}\text { Glioma patients }(\mathrm{N}=28) \\
\mathrm{HC}(\mathrm{N}=8)\end{array}$ & $\begin{array}{l}\text { Glioma-13o+ } \\
15 \sigma^{\top}(49 \mathrm{yrs}) \\
\text { HC-n.m. }\end{array}$ & $\begin{array}{c}3 \times 3500 \mathrm{rpm}\left(20^{\prime}\right)+ \\
\text { ExoQuick }^{\circledR}\end{array}$ & $\begin{array}{l}\text { Six overexpressed miRNAs were found on } \\
\text { EVs from glioma patients vs. HC. MiR-549a } \\
\text { and miR-502-5p expression predicted } \\
\text { prognosis in glioma patients. }\end{array}$ & [33] \\
\hline miR-301a & Glioma & Serum & $\begin{array}{l}\text { Glioma patients }(\mathrm{N}=60) \\
\mathrm{HC}(\mathrm{N}=43)\end{array}$ & $\begin{array}{l}\text { Glioma }-339+27 \sigma^{\top}(\text { n.m. }) \\
\text { HC-n.m. }\end{array}$ & $\begin{array}{c}3000 \times g\left(15^{\prime} \text { at } 4^{\circ} \mathrm{C}\right)+ \\
\text { ExoQuick }^{\circledR}\end{array}$ & $\begin{array}{l}\text { MiR-301a levels on EVs were upregulated } \\
\text { in glioma patients compared to HC, and } \\
\text { correlated with ascending pathological } \\
\text { grades. MiR-301a levels were significantly } \\
\text { reduced after surgical resection of primary } \\
\text { tumors and increased again during GM } \\
\text { recurrence, and were independently } \\
\text { associated with overall survival. }\end{array}$ & [40] \\
\hline
\end{tabular}


Table 2. Cont.

\begin{tabular}{|c|c|c|c|c|c|c|c|}
\hline Molecule & Disease & Sample Type & Sample Grouping and Size & $\begin{array}{c}\text { Patients Gender and } \\
\text { Mean Age }\end{array}$ & EVs Isolation Method & Key Findings & Ref. \\
\hline $\begin{array}{l}\text { miR-21, } \\
\text { miR-222, } \\
\text { miR-124-3p }\end{array}$ & Glioma & Serum & $\begin{array}{c}\text { Glioma patients }(\mathrm{N}=100) \\
\text { brain non-glial metastases } \\
\text { patients }(\mathrm{N}=11) \\
\mathrm{HC}(\mathrm{N}=30)\end{array}$ & 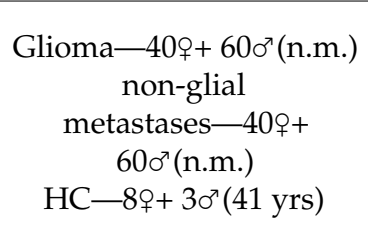 & $\begin{array}{c}3000 \times g\left(15^{\prime}\right)+ \\
\text { ExoQuick }^{\circledR}\end{array}$ & $\begin{array}{l}\text { The expression levels of miR-21, miR-222 } \\
\text { and miR-124-3p in EVs of patients with } \\
\text { high grade gliomas were significantly } \\
\text { higher than those of low grade gliomas and } \\
\text { HC, and were decreased in samples } \\
\text { obtained after surgery. }\end{array}$ & [46] \\
\hline miR-454-3p & Glioma & Serum & $\begin{array}{c}\text { Glioma patients }(\mathrm{N}=24) \\
\mathrm{HC}(\mathrm{N}=24)\end{array}$ & n.m. & $\begin{array}{l}\text { Ribo }^{\mathrm{TM}} \text { Exosome } \\
\text { Isolation Reagent }\end{array}$ & $\begin{array}{c}\text { MiR-454-3p was significantly } \\
\text { downregulated in tumor tissues, while it } \\
\text { was upregulated in EVs from the same } \\
\text { patients with glioma, corresponding to an } \\
\text { AUC of 0.8663. MiR-454-3p expression was } \\
\text { lower in the post-operative samples. High } \\
\text { miR- } 454-3 p \text { expression in EVs or low } \\
\text { expression in tissues was associated with } \\
\text { poor prognosis }\end{array}$ & [71] \\
\hline $\begin{array}{l}\operatorname{miR}-210, \\
\operatorname{miR}-5194 \\
\operatorname{miR}-449\end{array}$ & Glioma & Plasma & $\begin{array}{l}\text { GM patients }(\mathrm{N}=25), \text { LGA } \\
\text { patients }(\mathrm{N}=25), \\
\text { Head trauma patients } \\
(\mathrm{N}=15)\end{array}$ & $\begin{array}{l}\mathrm{GM}-60+19 \sigma^{\top} \text { (n.m.) } \\
\mathrm{LGA}-10++15 \sigma^{7} \text { (n.m.) } \\
\text { trauma-6o+ } 9 \sigma^{7} \text { (n.m.) }\end{array}$ & n.m. & $\begin{array}{l}\text { MiR-210 was upregulated in GM and LGA, } \\
\text { whereas miR-185, miR-5194, and miR-449 } \\
\text { were downregulated in GM and LGA } \\
\text { compared to trauma patients. MiR-5194 } \\
\text { and miR-449 were significantly decreased } \\
\text { in GM patients compared with LGA. }\end{array}$ & [94] \\
\hline
\end{tabular}

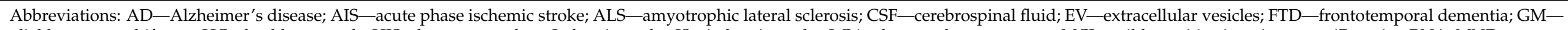

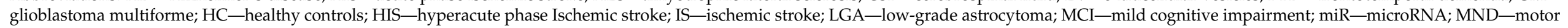

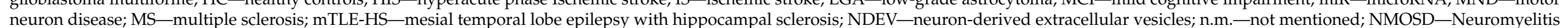

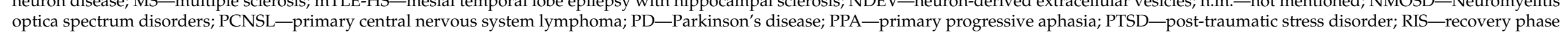

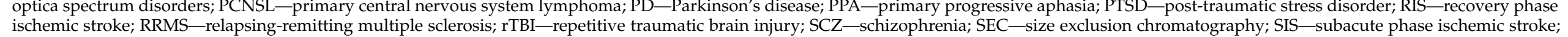
TBI-traumatic brain injury; VD—vascular dementia; yrs-years. 
Parkinson's disease (PD) is other common neurodegenerative disorder. Although PD can be described more correctly as a syndrome caused by different genetic and epigenetic alterations, a shared downstream result is the degeneration of dopamine-releasing axon terminals in the striatum and of corresponding neurons in the substantia nigra, which leads to impairment of motor and speech skills [100]. EVs have also been used as a diagnostic platform for PD. Indeed, increased $\alpha$-synuclein levels in plasma EVs were associated with $\mathrm{PD}$, and disease clinical severity, although results are inconsistent $[18,72,88]$. Moreover, reduced levels of CSF's EVs containing apolipoprotein A1 were associated with a higher risk of PD [21].

Multiple sclerosis (MS) and amyotrophic lateral sclerosis (ALS) are very different demyelinating diseases. MS is an autoimmune disease that affects the myelin sheath, which insulates nerve cell fibers in the brain and spinal cord [101], whereas ALS is a motor neuron disease that mainly affects the brain and spinal cord motor neuron cells [102]. For both diseases, several efforts have been made to find disease-related biomarkers in EVs isolated from patients' biological fluids, with a special emphasis in non-coding RNAs.

Non-coding RNAs (ncRNAs) are also generally found in circulating EVs. There are several ncRNA categories, commonly classified according to their size: the long ncRNAs (lncRNAs) with more than $200 \mathrm{nt}$, and the small ncRNAs (sncRNAs), including microRNAs (miRs), which present less than $200 \mathrm{nt}[103,104]$. These ncRNAs have been studied as specific disease "signatures" found in EVs in various disorders including MS/ALS. In fact, for all major group of CNS-related diseases mentioned in this review, published data on EVs ncRNAs have been assessed. For instance, in a recent study by Ebrahimkhani S. et al., the utility of serum exosome miRs as disease biomarkers of MS patients under treatment with fingolimod was assessed, and they found that several combinations of two or three miRNAs could discriminate active from quiescent disease with more than 90\% accuracy [79]. Likewise, for ALS, Banack et al. found that eight miRNAs, isolated from neural-enriched EVs, significantly distinguished ALS patients from controls, and thus might assist in early diagnosis of this disease [75].

Gliomas are glial cell-derived brain tumors, classified according to cell type, including ependymomas (ependymal cells), oligodendrogliomas (oligodendrocytes) and astrocytomas (astrocytes). The most common and malignant primary brain tumor, the grade IV astrocytoma/glioblastoma multiform belongs to this group of tumors [105]. Glioblastomaspecific or glioblastoma-rich protein and genetic material can be detected in EVs isolated from the biological fluids of glioblastoma's patients. The usefulness of using EVs as platforms for the analysis of specific biomarkers, which can help predict the disease outcome and prognosis of GM patients, have been recently established. For example, EGFRvIII is the oncogenic form of epidermal growth factor receptor (EGFR), never found in normal tissues. According to various reports, EGFRvIII protein, mRNA and DNA have been detected in plasma EVs isolated from patients with glioblastoma carrying EGFRvIII, but not in EVs isolated from noncancer patients [28,41,44]. Similarly, multiple studies have also shown that miR-21 levels are higher in EVs isolated from the serum and CSF of patients with glioblastoma. This finding is supported by the higher levels of miR-21 also described in clinical glioblastoma specimens $[20,27,46]$.

Traumatic brain injury (TBI), also known as intracranial injury, is a brain damage caused by external forces [106]. TBI classification can be based on severity (from mild to severe TBI), mechanism (closed or penetrating head injury), or other characteristics (for example, occurring in a specific location or widespread area). TBI usually causes neurological sequels, which can be seen even in mild TBI. Mild TBI may lead to acute symptoms, including chronic traumatic encephalopathy, cognitive impairment, dementia, movement disorders, and motor neuron dysfunction [107]. One of the main clinical challenges in TBI is to accurately identify its occurrence, and to determine the extent of CNS damage. Peltz et al. showed that in war veterans with a history of TBI, CNSenriched exosome concentration of pTAU, NfL, IL-6, TNFa are associated with cognitive 
impairment, which may assist clinicians in choosing a more appropriate treatment schedule and follow-up [89].

Psychiatric disorders, like schizophrenia (SCZ) or chronic depression, are estimated to affect a major percentage of the world population and are very difficult to diagnose and manage. Schizophrenia is a neurological disorder characterized by behavioral deficits, associated with impaired locomotor activity and cognitive defects. The diagnosis of schizophrenia is associated with demonstrable alterations in brain structure and changes in dopamine and glutamate neurotransmission in the cortex [108]. In this field, there is a demand for the discovery of biomarkers, which, if successful, can support clinicians in personalized treatment strategies. In this context, Du Y. et al. showed that the expression levels of specific miRs in EVs isolated from the blood of SCZ patients were sensitive to long-term medication [58].

Stroke, which can be categorized into ischemic or hemorrhagic stroke, affects 13.7 million people worldwide each year, and is the second leading cause of death, with 5.5 million deaths each year [109]. A stroke occurs when the blood supply to part of the brain is interrupted or reduced, limiting brain tissue from obtaining oxygen and nutrients, and generally causing brain damage [110]. Several authors explored the importance of the innate immune response as a contributor to the inflammatory response after stroke [111-113]. In this regard, Kerr et al. used a technique designated Simple Plex assay (an immunoassay in a microfluidic cartridge) to determine the presence and concentration of some inflammasome proteins in serum EVs of stroke patients [38]. The authors found that protein levels of ASC (caspase-recruitment domain) remained higher in serum-derived EVs from stroke samples, when compared to controls, and performed well as a potential biomarker for this pathological condition [38].

Major depressive disorder (MDD) is a debilitating mental disease characterized by persistent low mood. It affects the behavior as well as various physical functions, such as appetite and sleep [114]. Although the understanding of the neurobiology of MDD has improved in recent years, the knowledge of the mechanisms that may explain the most relevant aspects of the disease is limited. Nonetheless, MDD was associated with smaller hippocampal volumes, changes in activation or connectivity of neural networks, and also changes in the main neurobiological systems that mediate the stress response, including the hypothalamicpituitary-adrenal (HPA) axis, autonomic nervous system, and immune system [115,116]. The identification of susceptibility biomarkers that might identify individuals prone to depression and disease recurrence would improve treatment and allow for recurrence prevention. A series of studies by different research teams have implicated a systemic metabolic dysfunction known as insulin resistance in the pathophysiology and treatment of disorders of mood and cognition, including MDD [117,118]. Therefore, the insulin-receptor (IR) investigated in these studies was identified in brain areas associated with mood and cognition [119]. Indeed, Nasca et al. recently found that insulin-receptor substrate-1 (IRS-1) was highly abundant in neuronal-derived EVs isolated from plasma samples of MDD patients, compared to nonpathological controls, and that higher IRS-1 levels were associated with suicidality and anhedonia in those individuals. This data could lead to an improved strategy in the treatment of MDD patients [86].

\section{Future Perspectives and Conclusions}

Research based on EVs, specifically neuronal-derived EVs, is rapidly moving forward. We have now recognized a wide range of biological processes mediated by these molecules, and its importance into cell-cell communication, as well as disease spread within the CNS. With increasing knowledge about EVs from specific neurological diseases and the advances in technologies used to analyze these nanostructures, research is now moving towards clinical translation for biomarker platforms. For this, established and validated biomarkers are needed. Indeed, various single reports based on small cohorts have been published, but very few were validated by larger, cross-sectional investigations. The promising results so far point towards a future where brain-derived EVs could be used for not only for diagnosis 
of CNS-related disorders, but also for patient monitoring, and for studying the influence of the release of this specific EVs in behavioral and mental health related conditions.

Overall, EVs produced in the brain and circulating in peripheral fluids have become an incredible window to the brain, which is expected to assess the disease status of a given patient with great accuracy and simplicity. In the near future, one can anticipate that a relevant biomarker platform may move quickly into clinical context, to provide an enormous amount of information that may assist in clinical patients' follow-up. This may occur at the physician's office, as many technological solutions exist today to monitor such biomarkers using point-of-care devices. In a long-term perspective, one may anticipate that the information deriving from EVs may also act as an early disease warning system. It is only natural that the biological/biochemical information of such circulating EVs shall be better and more significant in time, considering the huge developments expected in the fields of nanotechnology, bioengineering and artificial intelligence. Specifically, when these are combined for the same purpose, even lower concentrations of a given pool of biomarkers in very complex samples might be detected. Finally, it will be indeed a breakthrough when such advanced biomarker panel from circulating EVs (that may well derive from CNS) becomes a tool to prevent disease progression.

Author Contributions: Conceptualization, S.M.-R., R.H. and C.J.; Methodology, S.M.-R., C.C.-M. and J.P.; Data collection, S.M.-R.; Writing-Original draft Preparation and Editing, S.M.-R.; Writing-Reviewing and Editing, G.B., S.J.V., E.R.S., G.S., R.H. and C.J.; Supervision, R.H. and C.J. All authors have read and agreed to the published version of the manuscript.

Funding: This research was funded by the MindGaP-H2020-FETOPEN-2018-2020, Grant agreement ID: 829040. S.M.-R., C.C.-M., and J.P. hold a fellowship from MindGaP.

Institutional Review Board Statement: Not applicable.

Informed Consent Statement: Not applicable.

Data Availability Statement: Data sharing not applicable.

Conflicts of Interest: The authors declare no conflict of interest. The funders had no role in the design of the study; in the collection, analyses, or interpretation of data; in the writing of the manuscript, or in the decision to publish the results.

\section{References}

1. Samanta, S.; Rajasingh, S.; Drosos, N.; Zhou, Z.; Dawn, B.; Rajasingh, J. Exosomes: New molecular targets of diseases. Acta Pharmacol. Sin. 2018, 39, 501-513. [CrossRef]

2. Lee, Y.; El Andaloussi, S.; Wood, M.J. Exosomes and microvesicles: Extracellular vesicles for genetic information transfer and gene therapy. Hum. Mol. Genet. 2012, 21, R125-R134. [CrossRef] [PubMed]

3. Gheinani, A.H.; Vogeli, M.; Baumgartner, U.; Vassella, E.; Draeger, A.; Burkhard, F.C.; Monastyrskaya, K. Improved isolation strategies to increase the yield and purity of human urinary exosomes for biomarker discovery. Sci. Rep. 2018, 8, 3945. [CrossRef]

4. Zhang, H.; Lyden, D. Asymmetric-flow field-flow fractionation technology for exomere and small extracellular vesicle separation and characterization. Nat. Protoc. 2019, 14, 1027-1053. [CrossRef]

5. Dos Anjos Pultz, B.; Andres Cordero da Luz, F.; Socorro Faria, S.; Peixoto Ferreira de Souza, L.; Cristina Brigido Tavares, P.; Alonso Goulart, V.; Fontes, W.; Ricardo Goulart, L.; Jose Barbosa Silva, M. The multifaceted role of extracellular vesicles in metastasis: Priming the soil for seeding. Int. J. Cancer 2017, 140, 2397-2407. [CrossRef]

6. Shi, M.; Sheng, L.; Stewart, T.; Zabetian, C.P.; Zhang, J. New windows into the brain: Central nervous system-derived extracellular vesicles in blood. Prog. Neurobiol. 2019, 175, 96-106. [CrossRef] [PubMed]

7. Matsumoto, J.; Stewart, T.; Banks, W.A.; Zhang, J. The Transport Mechanism of Extracellular Vesicles at the Blood-Brain Barrier. Curr. Pharm. Des. 2017, 23, 6206-6214. [CrossRef]

8. Brennan, K.; Martin, K.; FitzGerald, S.P.; O'Sullivan, J.; Wu, Y.; Blanco, A.; Richardson, C.; Mc Gee, M.M. A comparison of methods for the isolation and separation of extracellular vesicles from protein and lipid particles in human serum. Sci. Rep. 2020, 10, 1039. [CrossRef]

9. Fiandaca, M.S.; Kapogiannis, D.; Mapstone, M.; Boxer, A.; Eitan, E.; Schwartz, J.B.; Abner, E.L.; Petersen, R.C.; Federoff, H.J.; Miller, B.L.; et al. Identification of preclinical Alzheimer's disease by a profile of pathogenic proteins in neurally derived blood exosomes: A case-control study. Alzheimer's Dement. 2015, 11, 600-607e601. [CrossRef] [PubMed] 
10. Lachenal, G.; Pernet-Gallay, K.; Chivet, M.; Hemming, F.J.; Belly, A.; Bodon, G.; Blot, B.; Haase, G.; Goldberg, Y.; Sadoul, R. Release of exosomes from differentiated neurons and its regulation by synaptic glutamatergic activity. Mol. Cell Neurosci. 2011, 46, 409-418. [CrossRef]

11. Faure, J.; Lachenal, G.; Court, M.; Hirrlinger, J.; Chatellard-Causse, C.; Blot, B.; Grange, J.; Schoehn, G.; Goldberg, Y.; Boyer, V.; et al. Exosomes are released by cultured cortical neurones. Mol. Cell Neurosci. 2006, 31, 642-648. [CrossRef] [PubMed]

12. Goetzl, E.J.; Mustapic, M.; Kapogiannis, D.; Eitan, E.; Lobach, I.V.; Goetzl, L.; Schwartz, J.B.; Miller, B.L. Cargo proteins of plasma astrocyte-derived exosomes in Alzheimer's disease. FASEB J. 2016, 30, 3853-3859. [CrossRef] [PubMed]

13. Kramer-Albers, E.M.; Bretz, N.; Tenzer, S.; Winterstein, C.; Mobius, W.; Berger, H.; Nave, K.A.; Schild, H.; Trotter, J. Oligodendrocytes secrete exosomes containing major myelin and stress-protective proteins: Trophic support for axons? Proteomics Clin. Appl. 2007, 1, 1446-1461. [CrossRef]

14. Mustapic, M.; Eitan, E.; Werner, J.K., Jr.; Berkowitz, S.T.; Lazaropoulos, M.P.; Tran, J.; Goetzl, E.J.; Kapogiannis, D. Plasma extracellular vesicles enriched for neuronal origin: A potential window into brain pathologic processes. Front. Neurosci. 2017, 11, 278. [CrossRef] [PubMed]

15. Mobarrez, F.; Nybom, R.; Johansson, V.; Hultman, C.M.; Wallén, H.; Landén, M.; Wetterberg, L. Microparticles and microscopic structures in three fractions of fresh cerebrospinal fluid in schizophrenia: Case report of twins. Schizophr. Res. 2013, 143, 192-197. [CrossRef] [PubMed]

16. Kanhai, D.A.; de Kleijn, D.P.; Kappelle, L.J.; Uiterwaal, C.S.; van der Graaf, Y.; Pasterkamp, G.; Geerlings, M.I.; Visseren, F.L. Extracellular vesicle protein levels are related to brain atrophy and cerebral white matter lesions in patients with manifest vascular disease: The SMART-MR study. BMJ Open 2014, 4, e003824. [CrossRef]

17. Manterola, L.; Guruceaga, E.; Gállego Pérez-Larraya, J.; González-Huarriz, M.; Jauregui, P.; Tejada, S.; Diez-Valle, R.; Segura, V.; Samprón, N.; Barrena, C.; et al. A small noncoding RNA signature found in exosomes of GBM patient serum as a diagnostic tool. Neuro. Oncol. 2014, 16, 520-527. [CrossRef]

18. Shi, M.; Liu, C.; Cook, T.J.; Bullock, K.M.; Zhao, Y.; Ginghina, C.; Li, Y.; Aro, P.; Dator, R.; He, C.; et al. Plasma exosomal $\alpha$-synuclein is likely CNS-derived and increased in Parkinson's disease. Acta Neuropathol. 2014, 128, 639-650. [CrossRef]

19. Shao, H.; Chung, J.; Lee, K.; Balaj, L.; Min, C.; Carter, B.S.; Hochberg, F.H.; Breakefield, X.O.; Lee, H.; Weissleder, R. Chip-based analysis of exosomal mRNA mediating drug resistance in glioblastoma. Nat. Commun. 2015, 6, 6999. [CrossRef]

20. Shi, R.; Wang, P.Y.; Li, X.Y.; Chen, J.X.; Li, Y.; Zhang, X.Z.; Zhang, C.G.; Jiang, T.; Li, W.B.; Ding, W.; et al. Exosomal levels of miRNA-21 from cerebrospinal fluids associated with poor prognosis and tumor recurrence of glioma patients. Oncotarget 2015, 6, 26971-26981. [CrossRef]

21. Yang, Y.; Keene, C.D.; Peskind, E.R.; Galasko, D.R.; Hu, S.C.; Cudaback, E.; Wilson, A.M.; Li, G.; Yu, C.E.; Montine, K.S.; et al. Cerebrospinal fluid particles in Alzheimer disease and Parkinson disease. J. Neuropathol. Exp. Neurol. 2015, 74, 672-687. [CrossRef]

22. Goetzl, E.J.; Kapogiannis, D.; Schwartz, J.B.; Lobach, I.V.; Goetzl, L.; Abner, E.L.; Jicha, G.A.; Karydas, A.M.; Boxer, A.; Miller, B.L. Decreased synaptic proteins in neuronal exosomes of frontotemporal dementia and Alzheimer's disease. FASEB J. 2016, 30, 4141-4148. [CrossRef] [PubMed]

23. Ji, Q.; Ji, Y.; Peng, J.; Zhou, X.; Chen, X.; Zhao, H.; Xu, T.; Chen, L.; Xu, Y. Increased brain-specific MiR-9 and MiR-124 in the serum exosomes of acute ischemic stroke patients. PLoS ONE 2016, 11, e0163645. [CrossRef] [PubMed]

24. Lee, J.; McKinney, K.Q.; Pavlopoulos, A.J.; Han, M.H.; Kim, S.H.; Kim, H.J.; Hwang, S. Exosomal proteome analysis of cerebrospinal fluid detects biosignatures of neuromyelitis optica and multiple sclerosis. Clin. Chim. Acta 2016, 462, 118-126. [CrossRef]

25. Shi, M.; Kovac, A.; Korff, A.; Cook, T.J.; Ginghina, C.; Bullock, K.M.; Yang, L.; Stewart, T.; Zheng, D.; Aro, P.; et al. CNS tau efflux via exosomes is likely increased in Parkinson's disease but not in Alzheimer's disease. Alzheimer's Dement. 2016, 12, 1125-1131. [CrossRef]

26. Winston, C.N.; Goetzl, E.J.; Akers, J.C.; Carter, B.S.; Rockenstein, E.M.; Galasko, D.; Masliah, E.; Rissman, R.A. Prediction of conversion from mild cognitive impairment to dementia with neuronally derived blood exosome protein profile. Alzheimer's Dement. 2016, 3, 63-72. [CrossRef]

27. Akers, J.C.; Hua, W.; Li, H.; Ramakrishnan, V.; Yang, Z.; Quan, K.; Zhu, W.; Li, J.; Figueroa, J.; Hirshman, B.R.; et al. A cerebrospinal fluid microRNA signature as biomarker for glioblastoma. Oncotarget 2017, 8, 68769-68779. [CrossRef] [PubMed]

28. Figueroa, J.M.; Skog, J.; Akers, J.; Li, H.; Komotar, R.; Jensen, R.; Ringel, F.; Yang, I.; Kalkanis, S.; Thompson, R.; et al. Detection of wild-type EGFR amplification and EGFRvIII mutation in CSF-derived extracellular vesicles of glioblastoma patients. Neuro. Oncol. 2017, 19, 1494-1502. [CrossRef] [PubMed]

29. Mullins, R.J.; Mustapic, M.; Goetzl, E.J.; Kapogiannis, D. Exosomal biomarkers of brain insulin resistance associated with regional atrophy in Alzheimer's disease. Hum. Brain Mapp. 2017, 38, 1933-1940. [CrossRef]

30. Wang, S.; Liu, Z.; Ye, T.; Mabrouk, O.S.; Maltbie, T.; Aasly, J.; West, A.B. Elevated LRRK2 autophosphorylation in brain-derived and peripheral exosomes in LRRK2 mutation carriers. Acta Neuropathol. Commun. 2017, 5, 86. [CrossRef]

31. Welton, J.L.; Loveless, S.; Stone, T.; von Ruhland, C.; Robertson, N.P.; Clayton, A. Cerebrospinal fluid extracellular vesicle enrichment for protein biomarker discovery in neurological disease; multiple sclerosis. J. Extracell. Vesicles 2017, 6, 1369805. [CrossRef] [PubMed]

32. Yan, S.; Zhang, H.; Xie, W.; Meng, F.; Zhang, K.; Jiang, Y.; Zhang, X.; Zhang, J. Altered microRNA profiles in plasma exosomes from mesial temporal lobe epilepsy with hippocampal sclerosis. Oncotarget 2017, 8, 4136-4146. [CrossRef] 
33. Drusco, A.; Fadda, P.; Nigita, G.; Fassan, M.; Bottoni, A.; Gardiman, M.P.; Sacchi, D.; Calore, F.; Carosi, M.; Antenucci, A.; et al. circulating micrornas predict survival of patients with tumors of glial origin. EBioMedicine 2018, 30, 105-112. [CrossRef]

34. Galazka, G.; Mycko, M.P.; Selmaj, I.; Raine, C.S.; Selmaj, K.W. Multiple sclerosis: Serum-derived exosomes express myelin proteins. Mult. Scler. 2018, 24, 449-458. [CrossRef]

35. Goetzl, E.J.; Abner, E.L.; Jicha, G.A.; Kapogiannis, D.; Schwartz, J.B. Declining levels of functionally specialized synaptic proteins in plasma neuronal exosomes with progression of Alzheimer's disease. FASEB J. 2018, 32, 888-893. [CrossRef] [PubMed]

36. Guix, F.X.; Corbett, G.T.; Cha, D.J.; Mustapic, M.; Liu, W.; Mengel, D.; Chen, Z.; Aikawa, E.; Young-Pearse, T.; Kapogiannis, D.; et al. Detection of aggregation-competent tau in neuron-derived extracellular vesicles. Int. J. Mol. Sci. 2018, 19, 663. [CrossRef]

37. Huang, K.; Fang, C.; Yi, K.; Liu, X.; Qi, H.; Tan, Y.; Zhou, J.; Li, Y.; Liu, M.; Zhang, Y.; et al. The role of PTRF/Cavin1 as a biomarker in both glioma and serum exosomes. Theranostics 2018, 8, 1540-1557. [CrossRef]

38. Kerr, N.; García-Contreras, M.; Abbassi, S.; Mejias, N.H.; Desousa, B.R.; Ricordi, C.; Dietrich, W.D.; Keane, R.W.; de Rivero Vaccari, J.P. inflammasome proteins in serum and serum-derived extracellular vesicles as biomarkers of stroke. Front. Mol. Neurosci. 2018, 11, 309. [CrossRef]

39. Kuwano, N.; Kato, T.A.; Mitsuhashi, M.; Sato-Kasai, M.; Shimokawa, N.; Hayakawa, K.; Ohgidani, M.; Sagata, N.; Kubo, H.; Sakurai, T.; et al. Neuron-related blood inflammatory markers as an objective evaluation tool for major depressive disorder: An exploratory pilot case-control study. J. Affect. Disord. 2018, 240, 88-98. [CrossRef] [PubMed]

40. Lan, F.; Qing, Q.; Pan, Q.; Hu, M.; Yu, H.; Yue, X. Serum exosomal miR-301a as a potential diagnostic and prognostic biomarker for human glioma. Cell Oncol. 2018, 41, 25-33. [CrossRef] [PubMed]

41. Manda, S.V.; Kataria, Y.; Tatireddy, B.R.; Ramakrishnan, B.; Ratnam, B.G.; Lath, R.; Ranjan, A.; Ray, A. Exosomes as a biomarker platform for detecting epidermal growth factor receptor-positive high-grade gliomas. J. Neurosurg. 2018, 128, $1091-1101$. [CrossRef] [PubMed]

42. McKeever, P.M.; Schneider, R.; Taghdiri, F.; Weichert, A.; Multani, N.; Brown, R.A.; Boxer, A.L.; Karydas, A.; Miller, B.; Robertson, J.; et al. MicroRNA expression levels are altered in the cerebrospinal fluid of patients with young-onset Alzheimer's disease. Mol. Neurobiol. 2018, 55, 8826-8841. [CrossRef] [PubMed]

43. Pieragostino, D.; Cicalini, I.; Lanuti, P.; Ercolino, E.; di Ioia, M.; Zucchelli, M.; Zappacosta, R.; Miscia, S.; Marchisio, M.; Sacchetta, P.; et al. Enhanced release of acid sphingomyelinase-enriched exosomes generates a lipidomics signature in CSF of Multiple Sclerosis patients. Sci. Rep. 2018, 8, 3071. [CrossRef]

44. Reátegui, E.; van der Vos, K.E.; Lai, C.P.; Zeinali, M.; Atai, N.A.; Aldikacti, B.; Floyd, F.P., Jr.; Aimal, H.K.; Thapar, V.; Hochberg, F.H.; et al. Engineered nanointerfaces for microfluidic isolation and molecular profiling of tumor-specific extracellular vesicles. Nat. Commun. 2018, 9, 175. [CrossRef] [PubMed]

45. Ricklefs, F.L.; Alayo, Q.; Krenzlin, H.; Mahmoud, A.B.; Speranza, M.C.; Nakashima, H.; Hayes, J.L.; Lee, K.; Balaj, L.; Passaro, C.; et al. Immune evasion mediated by PD-L1 on glioblastoma-derived extracellular vesicles. Sci. Adv. 2018, 4, eaar2766. [CrossRef] [PubMed]

46. Santangelo, A.; Imbrucè, P.; Gardenghi, B.; Belli, L.; Agushi, R.; Tamanini, A.; Munari, S.; Bossi, A.M.; Scambi, I.; Benati, D.; et al. A microRNA signature from serum exosomes of patients with glioma as complementary diagnostic biomarker. J. Neurooncol. 2018, 136, 51-62. [CrossRef] [PubMed]

47. Schneider, R.; McKeever, P.; Kim, T.; Graff, C.; van Swieten, J.C.; Karydas, A.; Boxer, A.; Rosen, H.; Miller, B.L.; Laforce, R., Jr.; et al. Downregulation of exosomal miR-204-5p and miR-632 as a biomarker for FTD: A GENFI study. J. Neurol. Neurosurg. Psychiatr. 2018, 89, 851-858. [CrossRef]

48. Sproviero, D.; La Salvia, S.; Giannini, M.; Crippa, V.; Gagliardi, S.; Bernuzzi, S.; Diamanti, L.; Ceroni, M.; Pansarasa, O.; Poletti, A.; et al. Pathological proteins are transported by extracellular vesicles of sporadic amyotrophic lateral sclerosis patients. Front. Neurosci. 2018, 12, 487. [CrossRef]

49. Tan, S.K.; Pastori, C.; Penas, C.; Komotar, R.J.; Ivan, M.E.; Wahlestedt, C.; Ayad, N.G. Serum long noncoding RNA HOTAIR as a novel diagnostic and prognostic biomarker in glioblastoma multiforme. Mol. Cancer 2018, 17, 74. [CrossRef]

50. Wang, W.; Li, D.B.; Li, R.Y.; Zhou, X.; Yu, D.J.; Lan, X.Y.; Li, J.P.; Liu, J.L. Diagnosis of Hyperacute and Acute Ischaemic Stroke: The potential utility of exosomal MicroRNA-21-5p and MicroRNA-30a-5p. Cerebrovasc. Dis. 2018, 45, 204-212. [CrossRef]

51. Wei, H.; Xu, Y.; Xu, W.; Zhou, Q.; Chen, Q.; Yang, M.; Feng, F.; Liu, Y.; Zhu, X.; Yu, M.; et al. Serum exosomal miR-223 serves as a potential diagnostic and prognostic biomarker for dementia. Neuroscience 2018, 379, 167-176. [CrossRef]

52. Winston, C.N.; Goetzl, E.J.; Baker, L.D.; Vitiello, M.V.; Rissman, R.A. Growth hormone-releasing hormone modulation of neuronal exosome biomarkers in mild cognitive impairment. J. Alzheimer's Dis. 2018, 66, 971-981. [CrossRef]

53. Agliardi, C.; Guerini, F.R.; Zanzottera, M.; Bianchi, A.; Nemni, R.; Clerici, M. SNAP-25 in serum is carried by exosomes of neuronal origin and is a potential biomarker of Alzheimer's disease. Mol. Neurobiol. 2019, 56, 5792-5798. [CrossRef] [PubMed]

54. Athauda, D.; Gulyani, S.; Karnati, H.K.; Li, Y.; Tweedie, D.; Mustapic, M.; Chawla, S.; Chowdhury, K.; Skene, S.S.; Greig, N.H.; et al. Utility of neuronal-derived exosomes to examine molecular mechanisms that affect motor function in patients with Parkinson disease: A secondary analysis of the exenatide-PD Trial. JAMA Neurol. 2019, 76, 420-429. [CrossRef] [PubMed]

55. Cha, D.J.; Mengel, D.; Mustapic, M.; Liu, W.; Selkoe, D.J.; Kapogiannis, D.; Galasko, D.; Rissman, R.A.; Bennett, D.A.; Walsh, D.M. miR-212 and miR-132 are downregulated in neurally derived plasma exosomes of Alzheimer's patients. Front. Neurosci. 2019, 13, 1208. [CrossRef] 
56. Cicognola, C.; Brinkmalm, G.; Wahlgren, J.; Portelius, E.; Gobom, J.; Cullen, N.C.; Hansson, O.; Parnetti, L.; Constantinescu, R.; Wildsmith, K.; et al. Novel tau fragments in cerebrospinal fluid: Relation to tangle pathology and cognitive decline in Alzheimer's disease. Acta Neuropathol. 2019, 137, 279-296. [CrossRef]

57. Cumba Garcia, L.M.; Peterson, T.E.; Cepeda, M.A.; Johnson, A.J.; Parney, I.F. Isolation and analysis of plasma-derived exosomes in patients with glioma. Front. Oncol. 2019, 9, 651. [CrossRef]

58. Du, Y.; Yu, Y.; Hu, Y.; Li, X.W.; Wei, Z.X.; Pan, R.Y.; Li, X.S.; Zheng, G.E.; Qin, X.Y.; Liu, Q.S.; et al. Genome-wide, integrative analysis implicates exosome-derived microrna dysregulation in schizophrenia. Schizophr. Bull. 2019, 45, 1257-1266. [CrossRef] [PubMed]

59. Gámez-Valero, A.; Campdelacreu, J.; Reñé, R.; Beyer, K.; Borràs, F.E. Comprehensive proteomic profiling of plasma-derived Extracellular Vesicles from dementia with Lewy Bodies patients. Sci. Rep. 2019, 9, 13282. [CrossRef] [PubMed]

60. Goetzl, E.J.; Elahi, F.M.; Mustapic, M.; Kapogiannis, D.; Pryhoda, M.; Gilmore, A.; Gorgens, K.A.; Davidson, B.; Granholm, A.C.; Ledreux, A. Altered levels of plasma neuron-derived exosomes and their cargo proteins characterize acute and chronic mild traumatic brain injury. FASEB J. 2019, 33, 5082-5088. [CrossRef]

61. Jain, G.; Stuendl, A.; Rao, P.; Berulava, T.; Pena Centeno, T.; Kaurani, L.; Burkhardt, S.; Delalle, I.; Kornhuber, J.; Hüll, M.; et al. A combined miRNA-piRNA signature to detect Alzheimer's disease. Transl. Psychiatry 2019, 9, 250. [CrossRef]

62. Jones, P.S.; Yekula, A.; Lansbury, E.; Small, J.L.; Ayinon, C.; Mordecai, S.; Hochberg, F.H.; Tigges, J.; Delcuze, B.; Charest, A.; et al. Characterization of plasma-derived protoporphyrin-IX-positive extracellular vesicles following 5-ALA use in patients with malignant glioma. EBioMedicine 2019, 48, 23-35. [CrossRef] [PubMed]

63. Ko, J.; Hemphill, M.; Yang, Z.; Beard, K.; Sewell, E.; Shallcross, J.; Schweizer, M.; Sandsmark, D.K.; Diaz-Arrastia, R.; Kim, J.; et al. Multi-dimensional mapping of brain-derived extracellular vesicle MicroRNA biomarker for traumatic brain injury diagnostics. $J$. Neurotrauma 2019. [CrossRef]

64. Kuharić, J.; Grabušić, K.; Tokmadžić, V.S.; Štifter, S.; Tulić, K.; Shevchuk, O.; Lučin, P.; Šustić, A. Severe traumatic brain injury induces early changes in the physical properties and protein composition of intracranial extracellular vesicles. J. Neurotrauma 2019, 36, 190-200. [CrossRef] [PubMed]

65. Lee, M.Y.; Baxter, D.; Scherler, K.; Kim, T.K.; Wu, X.; Abu-Amara, D.; Flory, J.; Yehuda, R.; Marmar, C.; Jett, M.; et al. Distinct profiles of cell-free MicroRNAs in plasma of veterans with post-traumatic stress disorder. J. Clin. Med. 2019, 8, 963. [CrossRef] [PubMed]

66. Lewis, J.; Alattar, A.A.; Akers, J.; Carter, B.S.; Heller, M.; Chen, C.C. A pilot proof-of-principle analysis demonstrating dielectrophoresis (DEP) as a glioblastoma biomarker platform. Sci. Rep. 2019, 9, 10279. [CrossRef]

67. Muraoka, S.; Jedrychowski, M.P.; Tatebe, H.; DeLeo, A.M.; Ikezu, S.; Tokuda, T.; Gygi, S.P.; Stern, R.A.; Ikezu, T. Proteomic profiling of extracellular vesicles isolated from cerebrospinal fluid of former national football league players at risk for chronic traumatic encephalopathy. Front. Neurosci. 2019, 13, 1059. [CrossRef]

68. Otake, K.; Kamiguchi, H.; Hirozane, Y. Identification of biomarkers for amyotrophic lateral sclerosis by comprehensive analysis of exosomal mRNAs in human cerebrospinal fluid. BMC Med. Genomics 2019, 12, 7. [CrossRef]

69. Ricklefs, F.L.; Maire, C.L.; Reimer, R.; Dührsen, L.; Kolbe, K.; Holz, M.; Schneider, E.; Rissiek, A.; Babayan, A.; Hille, C.; et al. Imaging flow cytometry facilitates multiparametric characterization of extracellular vesicles in malignant brain tumours. $J$. Extracell Vesicles 2019, 8, 1588555. [CrossRef]

70. Saucier, D.; Wajnberg, G.; Roy, J.; Beauregard, A.P.; Chacko, S.; Crapoulet, N.; Fournier, S.; Ghosh, A.; Lewis, S.M.; Marrero, A.; et al. Identification of a circulating miRNA signature in extracellular vesicles collected from amyotrophic lateral sclerosis patients. Brain Res. 2019, 1708, 100-108. [CrossRef]

71. Shao, N.; Xue, L.; Wang, R.; Luo, K.; Zhi, F.; Lan, Q. miR-454-3p is an exosomal biomarker and functions as a tumor suppressor in glioma. Mol. Cancer Ther. 2019, 18, 459-469. [CrossRef] [PubMed]

72. Si, X.; Tian, J.; Chen, Y.; Yan, Y.; Pu, J.; Zhang, B. Central nervous system-derived exosomal alpha-synuclein in serum may be a biomarker in Parkinson's disease. Neuroscience 2019, 413, 308-316. [CrossRef]

73. Wang, H.; Jiang, D.; Li, W.; Xiang, X.; Zhao, J.; Yu, B.; Wang, C.; He, Z.; Zhu, L.; Yang, Y. Evaluation of serum extracellular vesicles as noninvasive diagnostic markers of glioma. Theranostics 2019, 9, 5347-5358. [CrossRef] [PubMed]

74. Winston, C.N.; Romero, H.K.; Ellisman, M.; Nauss, S.; Julovich, D.A.; Conger, T.; Hall, J.R.; Campana, W.; O’Bryant, S.E.; Nievergelt, C.M.; et al. Assessing neuronal and astrocyte derived exosomes from individuals with mild traumatic brain injury for markers of neurodegeneration and cytotoxic activity. Front. Neurosci. 2019, 13, 1005. [CrossRef] [PubMed]

75. Banack, S.A.; Dunlop, R.A.; Cox, P.A. An miRNA fingerprint using neural-enriched extracellular vesicles from blood plasma: Towards a biomarker for amyotrophic lateral sclerosis/motor neuron disease. Open Biol. 2020, 10, 200116. [CrossRef] [PubMed]

76. Chen, C.; Wu, Y.; Li, M.; Cui, C.; Zhao, Y.; Sun, X.; Wang, Y.; Liu, C.; Wu, H.; Zhong, X.; et al. Different exosomal microRNA profile in aquaporin-4 antibody positive neuromyelitis optica spectrum disorders. Front. Immunol. 2020, 11, 1064. [CrossRef]

77. Choi, J.; Kim, S.Y.; Kim, H.; Lim, B.C.; Hwang, H.; Chae, J.H.; Kim, K.J.; Oh, S.; Kim, E.Y.; Shin, J.S. Serum $\alpha$-synuclein and IL-1 $\beta$ are increased and correlated with measures of disease severity in children with epilepsy: Potential prognostic biomarkers? $B M C$ Neurol. 2020, 20, 85. [CrossRef]

78. Devoto, C.; Lai, C.; Qu, B.X.; Guedes, V.A.; Leete, J.; Wilde, E.; Walker, W.C.; Diaz-Arrastia, R.; Kenney, K.; Gill, J. Exosomal MicroRNAs in military personnel with mild traumatic brain injury: Preliminary results from the chronic effects of neurotrauma consortium biomarker discovery project. J. Neurotrauma 2020. [CrossRef] 
79. Ebrahimkhani, S.; Beadnall, H.N.; Wang, C.; Suter, C.M.; Barnett, M.H.; Buckland, M.E.; Vafaee, F. Serum exosome MicroRNAs predict multiple sclerosis disease activity after fingolimod treatment. Mol. Neurobiol. 2020, 57, 1245-1258. [CrossRef]

80. Eguchi, A.; Fukuda, S.; Kuratsune, H.; Nojima, J.; Nakatomi, Y.; Watanabe, Y.; Feldstein, A.E. Identification of actin network proteins, talin-1 and filamin-A, in circulating extracellular vesicles as blood biomarkers for human myalgic encephalomyelitis/chronic fatigue syndrome. Brain Behav. Immun. 2020, 84, 106-114. [CrossRef]

81. Goetzl, E.J.; Peltz, C.B.; Mustapic, M.; Kapogiannis, D.; Yaffe, K. Neuron-derived plasma exosome proteins after remote traumatic brain injury. J. Neurotrauma 2020, 37, 382-388. [CrossRef]

82. Goetzl, E.J.; Yaffe, K.; Peltz, C.B.; Ledreux, A.; Gorgens, K.; Davidson, B.; Granholm, A.C.; Mustapic, M.; Kapogiannis, D.; Tweedie, D.; et al. Traumatic brain injury increases plasma astrocyte-derived exosome levels of neurotoxic complement proteins. FASEB J. 2020, 34, 3359-3366. [CrossRef] [PubMed]

83. Guedes, V.A.; Kenney, K.; Shahim, P.; Qu, B.X.; Lai, C.; Devoto, C.; Walker, W.C.; Nolen, T.; Diaz-Arrastia, R.; Gill, J.M. Exosomal neurofilament light: A prognostic biomarker for remote symptoms after mild traumatic brain injury? Neurology 2020, 94, e2412-e2423. [CrossRef] [PubMed]

84. Mansur, R.B.; Delgado-Peraza, F.; Subramaniapillai, M.; Lee, Y.; Iacobucci, M.; Rodrigues, N.; Rosenblat, J.D.; Brietzke, E.; Cosgrove, V.E.; Kramer, N.E.; et al. Extracellular vesicle biomarkers reveal inhibition of neuroinflammation by infliximab in association with antidepressant response in adults with bipolar depression. Cells 2020, 9, 865. [CrossRef]

85. Mondello, S.; Guedes, V.A.; Lai, C.; Czeiter, E.; Amrein, K.; Kobeissy, F.; Mechref, Y.; Jeromin, A.; Mithani, S.; Martin, C.; et al. Circulating brain injury exosomal proteins following moderate-to-severe traumatic brain injury: Temporal profile, outcome prediction and therapy implications. Cells 2020, 9, 977. [CrossRef]

86. Nasca, C.; Dobbin, J.; Bigio, B.; Watson, K.; de Angelis, P.; Kautz, M.; Cochran, A.; Mathé, A.A.; Kocsis, J.H.; Lee, F.S.; et al. Insulin receptor substrate in brain-enriched exosomes in subjects with major depression: On the path of creation of biosignatures of central insulin resistance. Mol. Psychiatry 2020. [CrossRef] [PubMed]

87. Nie, C.; Sun, Y.; Zhen, H.; Guo, M.; Ye, J.; Liu, Z.; Yang, Y.; Zhang, X. Differential expression of plasma Exo-miRNA in neurodegenerative diseases by next-generation sequencing. Front. Neurosci. 2020, 14, 438. [CrossRef]

88. Niu, M.; Li, Y.; Li, G.; Zhou, L.; Luo, N.; Yao, M.; Kang, W.; Liu, J. A longitudinal study on $\alpha$-synuclein in plasma neuronal exosomes as a biomarker for Parkinson's disease development and progression. Eur. J. Neurol. 2020, 27, 967-974. [CrossRef] [PubMed]

89. Peltz, C.B.; Kenney, K.; Gill, J.; Diaz-Arrastia, R.; Gardner, R.C.; Yaffe, K. Blood biomarkers of traumatic brain injury and cognitive impairment in older veterans. Neurology 2020. [CrossRef]

90. Perrotte, M.; Haddad, M.; Le Page, A.; Frost, E.H.; Fulöp, T.; Ramassamy, C. Profile of pathogenic proteins in total circulating extracellular vesicles in mild cognitive impairment and during the progression of Alzheimer's disease. Neurobiol. Aging 2020, 86, 102-111. [CrossRef]

91. Puigdelloses, M.; González-Huárriz, M.; García-Moure, M.; Martínez-Vélez, N.; Esparragosa Vázquez, I.; Bruna, J.; Zandio, B.; Agirre, A.; Marigil, M.; Petrirena, G.; et al. RNU6-1 in circulating exosomes differentiates GBM from non-neoplastic brain lesions and PCNSL but not from brain metastases. Neurooncol. Adv. 2020, 2, vdaa010. [CrossRef]

92. Ricklefs, F.L.; Maire, C.L.; Matschke, J.; Dührsen, L.; Sauvigny, T.; Holz, M.; Kolbe, K.; Peine, S.; Herold-Mende, C.; Carter, B.; et al. FASN is a biomarker enriched in malignant glioma-derived extracellular vesicles. Int. J. Mol. Sci. 2020, 21, 1931. [CrossRef]

93. Serpente, M.; Fenoglio, C.; D’Anca, M.; Arcaro, M.; Sorrentino, F.; Visconte, C.; Arighi, A.; Fumagalli, G.G.; Porretti, L.; Cattaneo, A.; et al. MiRNA profiling in plasma neural-derived small extracellular vesicles from patients with Alzheimer's disease. Cells 2020, 9, 1443. [CrossRef]

94. Tabibkhooei, A.; Izadpanahi, M.; Arab, A.; Zare-Mirzaei, A.; Minaeian, S.; Rostami, A.; Mohsenian, A. Profiling of novel circulating microRNAs as a non-invasive biomarker in diagnosis and follow-up of high and low-grade gliomas. Clin. Neurol. Neurosurg. 2020, 190, 105652. [CrossRef]

95. Tan, N.; Hu, S.; Hu, Z.; Wu, Z.; Wang, B. Quantitative proteomic characterization of microvesicles/exosomes from the cerebrospinal fluid of patients with acute bilirubin encephalopathy. Mol. Med. Rep. 2020, 22, 1257-1268. [CrossRef] [PubMed]

96. Wang, D.; Wang, P.; Bian, X.; Xu, S.; Zhou, Q.; Zhang, Y.; Ding, M.; Han, M.; Huang, L.; Bi, J.; et al. Elevated plasma levels of exosomal BACE1-AS combined with the volume and thickness of the right entorhinal cortex may serve as a biomarker for the detection of Alzheimer's disease. Mol. Med. Rep. 2020, 22, 227-238. [CrossRef] [PubMed]

97. Galbo, P.M., Jr.; Ciesielski, M.J.; Figel, S.; Maguire, O.; Qiu, J.; Wiltsie, L.; Minderman, H.; Fenstermaker, R.A. Circulating CD9+/GFAP+/survivin+ exosomes in malignant glioma patients following survivin vaccination. Oncotarget 2017, 8, 114722114735. [CrossRef] [PubMed]

98. Masters, C.L.; Bateman, R.; Blennow, K.; Rowe, C.C.; Sperling, R.A.; Cummings, J.L. Alzheimer's disease. Nat. Rev. Dis. Primers 2015, 1, 15056. [CrossRef] [PubMed]

99. Petersen, R.C. Clinical practice. Mild cognitive impairment. N. Engl. J. Med. 2011, 364, 2227-2234. [CrossRef]

100. Poewe, W.; Seppi, K.; Tanner, C.M.; Halliday, G.M.; Brundin, P.; Volkmann, J.; Schrag, A.E.; Lang, A.E. Parkinson disease. Nat. Rev. Dis. Primers 2017, 3, 17013. [CrossRef]

101. Filippi, M.; Bar-Or, A.; Piehl, F.; Preziosa, P.; Solari, A.; Vukusic, S.; Rocca, M.A. Multiple sclerosis. Nat. Rev. Dis. Primers 2018, 4, 43. [CrossRef] [PubMed] 
102. Hardiman, O.; Al-Chalabi, A.; Chio, A.; Corr, E.M.; Logroscino, G.; Robberecht, W.; Shaw, P.J.; Simmons, Z.; van den Berg, L.H. Amyotrophic lateral sclerosis. Nat. Rev. Dis. Primers 2017, 3, 17071. [CrossRef] [PubMed]

103. Mattick, J.S.; Rinn, J.L. Discovery and annotation of long noncoding RNAs. Nat. Struct. Mol. Biol. 2015, 22, 5-7. [CrossRef] [PubMed]

104. Ramalho-Carvalho, J.; Fromm, B.; Henrique, R.; Jeronimo, C. Deciphering the function of non-coding RNAs in prostate cancer. Cancer Metastasis Rev. 2016, 35, 235-262. [CrossRef] [PubMed]

105. Louis, D.N.; Perry, A.; Reifenberger, G.; von Deimling, A.; Figarella-Branger, D.; Cavenee, W.K.; Ohgaki, H.; Wiestler, O.D.; Kleihues, P.; Ellison, D.W. The 2016 World Health Organization classification of tumors of the central nervous system: A summary. Acta Neuropathol. 2016, 131, 803-820. [CrossRef] [PubMed]

106. Blennow, K.; Brody, D.L.; Kochanek, P.M.; Levin, H.; McKee, A.; Ribbers, G.M.; Yaffe, K.; Zetterberg, H. Traumatic brain injuries. Nat. Rev. Dis. Primers 2016, 2, 16084. [CrossRef] [PubMed]

107. Levin, H.S.; Diaz-Arrastia, R.R. Diagnosis, prognosis, and clinical management of mild traumatic brain injury. Lancet Neurol. 2015, 14, 506-517. [CrossRef]

108. Marder, S.R.; Cannon, T.D. Schizophrenia. N. Engl. J. Med. 2019, 381, 1753-1761. [CrossRef]

109. Collaborators, G.B.D.S. Global, regional, and national burden of stroke, 1990-2016: A systematic analysis for the Global Burden of Disease Study 2016. Lancet Neurol. 2019, 18, 439-458. [CrossRef]

110. Campbell, B.C.V.; De Silva, D.A.; Macleod, M.R.; Coutts, S.B.; Schwamm, L.H.; Davis, S.M.; Donnan, G.A. Ischaemic stroke. Nat. Rev. Dis. Primers 2019, 5, 70. [CrossRef]

111. Xu, X.; Jiang, Y. The Yin and Yang of innate immunity in stroke. Biomed. Res. Int. 2014, 2014, 807978. [CrossRef]

112. Brand, F.J., 3rd; de Rivero Vaccari, J.C.; Mejias, N.H.; Alonso, O.F.; de Rivero Vaccari, J.P. RIG-I contributes to the innate immune response after cerebral ischemia. J. Inflamm. 2015, 12, 52. [CrossRef] [PubMed]

113. Neumann, S.; Shields, N.J.; Balle, T.; Chebib, M.; Clarkson, A.N. Innate immunity and inflammation post-stroke: An alpha7nicotinic agonist perspective. Int. J. Mol. Sci. 2015, 16, 29029-29046. [CrossRef] [PubMed]

114. Otte, C.; Gold, S.M.; Penninx, B.W.; Pariante, C.M.; Etkin, A.; Fava, M.; Mohr, D.C.; Schatzberg, A.F. Major depressive disorder. Nat. Rev. Dis. Primers 2016, 2, 16065. [CrossRef] [PubMed]

115. Kupfer, D.J.; Frank, E.; Phillips, M.L. Major depressive disorder: New clinical, neurobiological, and treatment perspectives. Lancet 2012, 379, 1045-1055. [CrossRef]

116. Etkin, A.; Buchel, C.; Gross, J.J. The neural bases of emotion regulation. Nat. Rev. Neurosci. 2015, 16, 693-700. [CrossRef] [PubMed]

117. Watson, K.; Nasca, C.; Aasly, L.; McEwen, B.; Rasgon, N. Insulin resistance, an unmasked culprit in depressive disorders: Promises for interventions. Neuropharmacology 2018, 136, 327-334. [CrossRef]

118. Nasca, C.; Rasgon, N.; McEwen, B. An emerging epigenetic framework of systemic and central mechanisms underlying stressrelated disorders. Neuropsychopharmacology 2019, 44, 235-236. [CrossRef]

119. Duarte, A.I.; Moreira, P.I.; Oliveira, C.R. Insulin in central nervous system: More than just a peripheral hormone. J. Aging Res. 2012, 2012, 384017. [CrossRef] 